\title{
Steel fibers pull-out after exposure to high temperatures and its contribution to the residual mechanical behavior of high strength concrete
}

\author{
Gonzalo Ruano $^{\mathrm{a}, *}$, Facundo Isla ${ }^{\mathrm{a}}$, Bibiana Luccioni ${ }^{\mathrm{a}}$, Raúl Zerbino ${ }^{\mathrm{b}}$, Graciela Giaccio ${ }^{\mathrm{c}}$ \\ ${ }^{a}$ CONICET, Structures Institute, National University of Tucumán, Av. Independencia 1800, S.M. de Tucumán, Argentina \\ ${ }^{\mathrm{b}}$ CONICET, LEMIT, Engineering Faculty, National University of La Plata, Argentina

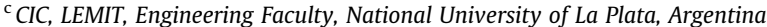

\section{H I G H L I G H T S}

- The effect of high temperatures up to $500{ }^{\circ} \mathrm{C}$ on fiber reinforced concrete is analyzed.

- A numerical model that reproduces test results and is useful for design is presented.

- Degradation of the different mechanisms contributing to pull-out behavior is studied.

- Reduction of pull-out strength is lower than decrease of matrix compressive strength.

- Great part of post-peak flexure strength is preserved.

\section{A R T I C L E I N F O}

\section{Article history:}

Received 30 August 2017

Received in revised form 11 December 2017

Accepted 17 December 2017

\section{Keywords:}

High temperature

Steel fibers pull-out

High strength fiber reinforced concrete

Numerical model

\begin{abstract}
A B S T R A C T
Many concrete structures are exposed to high temperatures that produce material deterioration involving stiffness and strength loss. Although residual mechanical behavior of steel fiber reinforced concrete subjected to high temperatures has been studied in the last decades, the effect of the deterioration of each component of the composite behavior has not been assessed. This information together with a mesomechanical model can be very useful for the design of steel fiber reinforced concrete to be used in structures that are expected to be exposed to high temperatures.

This paper analyzes the effect of temperature on steel fibers pull-out mechanism from a high strength concrete matrix and its contribution to the residual mechanical behavior of Steel Fiber Reinforced High Strength Concrete (SFRHSC). Pull-out tests of straight and hooked end fibers and uniaxial tension tests on the fiber filaments exposed to room and high temperature $\left(300{ }^{\circ} \mathrm{C}, 375^{\circ} \mathrm{C}\right.$ and $475{ }^{\circ} \mathrm{C}$ ) were performed. Additionally, two SFRHSC incorporating $30 \mathrm{~kg} / \mathrm{m}^{3}$ and $60 \mathrm{~kg} / \mathrm{m}^{3}$ of hooked end steel fibers and a plain High Strength Concrete (HSC) exposed to the same temperatures were studied. Uniaxial compression tests and bending tests on notched prisms were used to characterize the composite material. The experimental results were analyzed with the aid of a pull-out model and a meso-model for SFRHSC, both developed by the authors. It is shown that hooked end fibers pull-out strength was reduced after the exposure to high temperatures. Since concrete strength only contributes in a small region surrounding the hooks, the pull-out strength reduction can be mainly attributed to the reduction of steel strength and frictional effects due to high temperature exposition. HSC tension strength reduction begins earlier and it is proportionally greater than pull-out strength reduction. As a consequence, HSC bending strength decreases faster than SFRHSC strength.
\end{abstract}

(c) 2017 Elsevier Ltd. All rights reserved.

\section{Introduction}

Many structures like industrial plants or nuclear power plants are expected to be exposed to high temperatures due to their

\footnotetext{
* Corresponding author.

E-mail address: gonzalo.ruano@conicet.gov.ar (G. Ruano).
}

functions. In addition, other structures can be accidentally exposed to thermal risk (e.g. tunnels, tall buildings) that threat personal and property safety.

Nowadays, cementitious composites are increasingly being used in construction and they are normally designed for specific applications [1] with special characteristics like high strength, low permeability and improved durability [2]. The counterpart of 
these superior performance cementitious materials are brittleness and higher vulnerability to high temperature exposure [3]. The addition of fibers can help counteracting these disadvantages and improving the composite behavior of Fiber Reinforced Concrete (FRC).

It is well known that FRC failure is strongly related to the fiber pull-out mechanism. Thus, a comprehension of the factors affecting the pull-out mechanism combined with other significant variables as the density and orientation of fibers in FRC is required to model FRC behavior [4]. Steel fiber pull-out involves fiber/matrix debonding and frictional sliding, but pull-out strength is mainly due to mechanical interlocking introduced by fiber conformation [4]. Pull-out tests made by Naaman and Najm [5] on different types of steel fibers (smooth, deformed and hooked end) embedded in mortar matrices with compressive strengths from 33 to 60 $\mathrm{MPa}$ indicate that deformed fibers resist pull-out in an oscillatory way, while hooked end fibers resistance decreases as the hook is straightened and travels along the matrix tunnel. As expected, pull-out load strength increases with the fiber embedded length but increments are more evident in straight fibers than in hooked end fibers [6,7]. Pull-out tests of fibers with an inclination of $30^{\circ}$ show an increase of strength with respect to aligned fibers but the pull-out strength decreases for inclinations greater than $45^{\circ}$ $[6,8]$. It was usually found that the lower the $w / c$ ratio, the higher the concrete failure load. However, the $\mathrm{w} / \mathrm{c}$ ratio plays a minor role in the pull-out behavior [9,10]. It was also observed that the fluidity of the matrix improves bond strength of straight and twisted steel fibers [11]. Results of single fiber pull-out tests for deformed and smooth steel fiber embedded in very-high strength concrete matrices confirm that the maximum pull-out load and the total pull-out energy increase as matrix strength increases for smooth, flat end and hooked end fibers that did not rupture [12-14].

The residual response of FRC after exposure to high temperatures strongly depends on fibers material. Many researchers have studied the behavior of fiber composites incorporating steel fibers, polypropylene fibers or a combination of both, after the exposure to high temperatures. Steel fibers improve residual mechanical properties [15] of concrete exposed to high temperature [16,17], being the gain more marked in tension $[18,19]$ than in compression [20,21].

The reductions in flexural strength are lower in steel FRC (SFRC) than in plain concrete and the post-peak strength is less affected than first-crack strength. Bozkurt [22] showed that steel macro fibers provide better flexural strength to self-compacting lightweight concrete exposed to high temperatures than hybrid fibers. Khaliq and Kodur [18] also found that steel fibers improve tensile strength of self-compacting concrete tested at temperatures up to $400^{\circ} \mathrm{C}$.

Some SFRCs exposed to high temperatures exhibit strain hardening and keep an almost constant load capacity during the postpeak [23]. Similar results were obtained for slurry infiltrated fiber concrete (SIFCON) over $300{ }^{\circ} \mathrm{C}$ [24]; flexure strength decreases with temperature but behavior is more plastic due to the fiberslip mechanism. For more severe exposure conditions, the degradation of the material is reflected by an increase in non-linearity [23]. Beglarigale et al. [24] attributed the stiffness and strength loss of SIFCON at high temperatures to the effect of micro-cracks that are formed at the areas of unhydrated grains and the $\mathrm{Ca}(\mathrm{OH})_{2}$ concentration, the decomposition of calcium hydroxide that can lead to a damage as a result of lime expansion during the cooling period, increase in porosity, decomposition of hydration products (above $400{ }^{\circ} \mathrm{C}$ ), destruction of $\mathrm{C}-\mathrm{S}-\mathrm{H}$ structure and decomposition of the limestone aggregate and powders $\left(\mathrm{CaCO}_{3}\right)$ around $750{ }^{\circ} \mathrm{C}$. Moreover, the deterioration of SIFCON under temperatures higher than $600{ }^{\circ} \mathrm{C}$ can be attributed to the oxidation of external surface of steel fibers that produces a reduction of fibers cross section and fibermatrix bond strength [24].

Like in plain concrete, the Young's modulus of fiber reinforced reactive powder concrete decreases with increasing temperature and the stiffness loss is faster than the compressive strength loss $[25,26]$. The compression stress-strain relationship of SFRC after temperature exposure presents increasing strength in the 200$300{ }^{\circ} \mathrm{C}$ range, then decreases in the $300-700{ }^{\circ} \mathrm{C}$ range and the stress-strain curves become flatter. Similar results were verified in the case of steel fiber reinforced recycled aggregate concrete [27] and hybrid steel and polyvinyl alcohol fiber reinforced concrete [28]. Favorable effects of steel fibers in residual compressive strength and surface cracking of concrete subjected to high temperatures were observed for thin fibers and not for thick fibers [29]. The residual behavior depends more on the volume fraction and aspect ratio than on fiber's axis shape (straight, hooked end, twisted) [21].

It was proved that testing conditions, i.e. performed while the specimens are still hot or after cooling (residual state), influence concrete mechanical behavior [1]. Nevertheless, the differences in mechanical properties are insignificant [30]; thus, residual mechanical properties can be safely used.

Some negative effects of steel fibers addition in the response of FRC after very high temperature exposure have been observed. Cracks between matrix and steel fibers appeared as a result of different thermal expansion coefficients and oxidation darken FRC [25]. At $750^{\circ} \mathrm{C}$ steel fibers suffer partial melting and morphology and composition of fibers core can be affected. Partially melted fibers fill concrete cracks, fibers diameter is increased by oxide layer and they become brittle. All these phenomena result in a compromise of fiber pull-out mechanism [31]. Nevertheless, some of the benefits of adding steel fiber to concrete are retained after the exposure to high temperatures up to $1200^{\circ} \mathrm{C}[16,32]$.

The research concerning the behavior of SFRC after heating have focused the attention on the composite behavior. Although there are experimental results from pull-out tests [33] available in the literature and the deterioration produced by other phenomena like corrosion [34,35] or alkali silica reaction [36-39] has been studied, the effect of temperature on a single fiber pull-out has usually been indirectly analyzed from FRC tension tests results $[31,38,39]$. Recently, Abdallah et al. [40] studied the pull-out behavior of steel fibers embedded in concrete after exposure to elevated temperatures. They found that pull-out behavior of straight fibers is significantly influenced by high temperature. In contrast, pull-out behavior of hooked end steel fibers is practically not affected by temperature up to $400{ }^{\circ} \mathrm{C}$, while the pull-out strength shows a strong reduction for higher temperatures.

A comprehensive numerical study of the effect of temperature on the pull-out mechanism and on SFRC residual behavior is not yet available. Considering that fiber pull-out is the main mechanism responsible of FRC behavior, this paper experimentally and numerically analyzes the effect of high temperature on steel fiber pull-out response and identifies its impact on Steel Fiber Reinforced High Strength Concrete (SFRHSC) residual mechanical behavior.

\section{Experimental program}

Pull-out tests were performed on single hooked end and straight smooth steel fibers embedded in High Strength Concrete (HSC) matrix. These specimens were divided in four groups and three of them were exposed to high temperatures. In addition, individual steel fibers were also exposed to the same temperatures to characterize their residual tension behavior. The residual properties of a base HSC and two SFRHSC, under uniaxial compression and flexure were also evaluated. 


\subsection{Materials}

Concrete was prepared with ordinary Portland cement, high range water reducer admixture, natural siliceous sand and 12 $\mathrm{mm}$ maximum size granitic crushed stone. Table 1 presents the proportions and the fresh properties of base HSC. Steel hooked end fibers of $50 \mathrm{~mm}$ length and $1 \mathrm{~mm}$ diameter $(1 / \mathrm{d}=50)$ were used. Concretes SFRHSC30 and SFRHSC60 were obtained incorporating $30 \mathrm{~kg} / \mathrm{m}^{3}$ and $60 \mathrm{~kg} / \mathrm{m}^{3}$ of fibers to the base concrete. SFRHSC slumps were $60 \mathrm{~mm}$ and $40 \mathrm{~mm}$ respectively.

\subsection{Experimental methods}

For pull-out tests, 22 specimens with a single embedded fiber were cast using the HSC as matrix. At the same time, 16 identical specimens were cast with the same fibers without the hook (i.e. it was cut, as representative of straight fibers) to evaluate the effect of fiber/matrix adherence and the effect of the fiber hook by comparison with hooked end fibers. Pull-out specimens consist of a single fiber partially embedded in a $40 \times 40 \times 60 \mathrm{~mm}$ prism. The fiber was fixed between two $40 \times 40 \times 20 \mathrm{~mm}$ plywood sheets leaving $36 \mathrm{~mm}$ to be embedded in concrete. This plywood cube with the fiber was placed in a $40 \times 40 \times 160 \mathrm{~mm}$ mold and the concrete was poured around the fiber.

Fifteen cylinders of $100 \mathrm{~mm}$ diameter and $200 \mathrm{~mm}$ height and 12 prisms of $105 \times 75 \times 430 \mathrm{~mm}$ were cast with each concrete for compression and flexure tests respectively. The dimensions of the beams are representative of the thickness of SFRC reinforcements used for concrete structures.

Pull-out specimens, fibers, cylinders and prisms were divided in four groups. Group $20^{\circ} \mathrm{C}$ was left at room temperature as reference; the other three were oven dried at $105^{\circ} \mathrm{C}$ for $24 \mathrm{~h}$ and then were heated up to $300{ }^{\circ} \mathrm{C}, 375^{\circ} \mathrm{C}$ or $475^{\circ} \mathrm{C}$ maximum temperatures and finally cooled in the furnace to room temperature. The groups are identified with the maximum exposure temperature value. All specimens in each group were heated together. Fig. 1 presents the three temperature histories applied. The evolution of both the furnace temperature and the temperature measured with a thermocouple inserted in the center of a cylindrical specimen is shown.

Pull-out tests were performed upside down with the free end of the fiber clamped with the bottom hydraulic grip while a specially designed grip pulled upwards from the specimen body [33]. Load was measured with a $2 \mathrm{~N}$ sensibility load cell composed of two dynamometric rings with LVDTs. Two LVDTs with $50 \mathrm{~mm}$ range and $5 \mu \mathrm{m}$ sensibility, located at both sides of the specimens measured the displacements. Displacement was applied at a rate of $20 \mathrm{~mm} / \mathrm{min}$.

Tension tests of steel fibers were performed with a servocontrolled press applying displacements at a rate of $0.2 \mathrm{~mm} / \mathrm{min}$ to assess their strength and strain capacity after the exposure to high temperatures.

Table 1

Mix proportions and properties of fresh concrete.

\begin{tabular}{ll}
\hline & HSC \\
\hline Cement $\left[\mathrm{kg} / \mathrm{m}^{3}\right]$ & 488 \\
Water $\left[\mathrm{kg} / \mathrm{m}^{3}\right]$ & 161 \\
Sand $\left[\mathrm{kg} / \mathrm{m}^{3}\right]$ & 930 \\
Coarse $\left[\mathrm{kg} / \mathrm{m}^{3}\right]$ & 835 \\
Superplasticizer $\left[\mathrm{kg} / \mathrm{m}^{3}\right]$ & 10.5 \\
Air content $[\%]$ & 3.5 \\
Slump $[\mathrm{mm}]$ & 80 \\
\hline
\end{tabular}

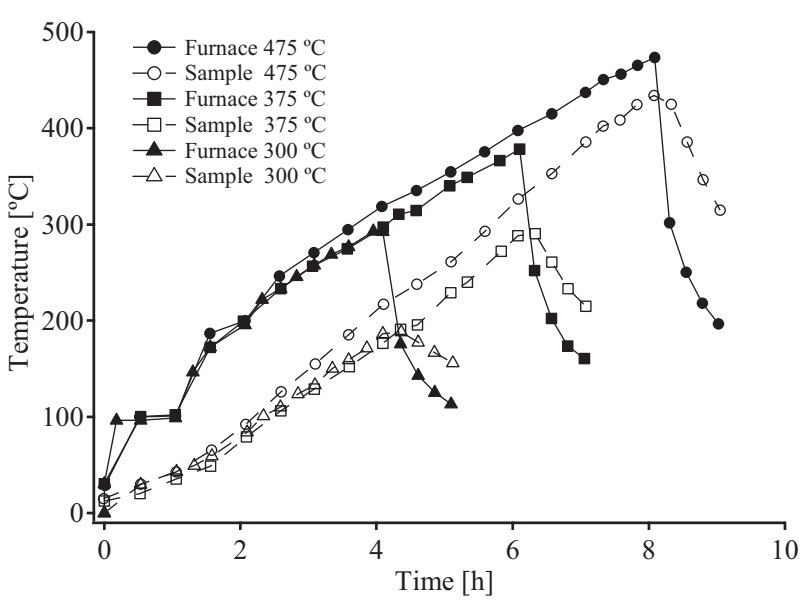

Fig. 1. Temperature history.

The Ultrasonic Pulse Velocity (UPV) was measured before and after concrete prisms were exposed to high temperature to evaluate the damage produced by heat treatment [23]. The UPV was obtained through direct transmission using portable equipment with a $54 \mathrm{kHz}$ transducer and a $0.1 \mu$ s resolution.

Uniaxial compression tests were performed on HSC and SFRHSC cylinders. The compressive strength and the elasticity modulus were determined following the general guidelines of ASTM C 39 [41] and ASTM C 469 [42] respectively. The axial deformation was measured with $50 \mathrm{~mm}$ range and $1 \mu \mathrm{m}$ sensibility Linear Variable Differential Transducers (LVDTs).

Three points bending tests on notched HSC and SFRHSC beams were performed under displacement control following the general guidelines of the EN 14651 [43] standard. Displacement was applied at a rate of $0.05 \mathrm{~mm} / \mathrm{min}$ up to $0.1 \mathrm{~mm}$ and then, a rate of $0.2 \mathrm{~mm} / \mathrm{min}$ up to $10 \mathrm{~mm}$ was applied. Load, deflections on both sides relative to the beam axis and Crack Mouth Opening Displacement (CMOD) in the bottom of the beam were measured with 50 $\mathrm{mm}$ range and $1 \mu \mathrm{m}$ sensibility LVDTs.

The stress at the limit of proportionality $\left(f_{\mathrm{L}}\right)$ corresponding to the maximum load up to a CMOD of $0.05 \mathrm{~mm}$, and the residual stresses $f_{\mathrm{R} 1}$ and $f_{\mathrm{R} 3}$, which are the nominal stresses calculated for the post peak loads corresponding to a CMOD of $0.5 \mathrm{~mm}$ and 2.5 $\mathrm{mm}$, used in the fib Model Code 2010 [44] to classify FRC were calculated. As in these experiments prisms were not standard specimens of $150 \mathrm{~mm}$ height, $f_{\mathrm{L}}, f_{\mathrm{R} 1}$ and $f_{\mathrm{R} 3}$ were calculated for CMODs of $0.033 \mathrm{~mm}, 0.33 \mathrm{~mm}$ and $1.66 \mathrm{~mm}$ respectively, keeping the notch/height and height/span ratios as in standard prisms. Thus, the parameters correspond to the same rotations established by EN 14651 [45]. In damaged concrete the non-linear behavior starts for lower stresses than for undamaged concrete. In most damaged SFRHSCs a peak load can be seen for CMODs higher than $0.033 \mathrm{~mm}$ and lower than $0.2 \mathrm{~mm}$, then a first peak stress $\left(f_{\mathrm{P}}\right)$ was calculated as the maximum stress for CMODs smaller than $0.2 \mathrm{~mm}$. This stress is assumed to be representative of the matrix strength. A measure of the energy dissipated $\left(G_{F}\right)$ was also calculated as the area under the stress-CMOD curves up to CMOD of $1 \mathrm{~mm}$ for HSC and up to $2.5 \mathrm{~mm}$ for SFRHSC. At the end of bending tests, the prisms were completely separated in two halves and the number of fibers was counted on both fractured surfaces to calculate the fibers density.

\subsection{Test results}

\subsubsection{Fiber pull-out tests}

Fig. 2 presents the load-displacement curves obtained from pull-out tests of straight and hooked end fibers previously exposed 
to the different temperature histories. As expected, hooked end fibers exhibit greater pull-out strength than straight fibers. Pullout results for straight fibers show high dispersion but the average pull-out strength decreases with temperature increase. In contrast, hooked end fibers show no change in pull-out response up to 375 ${ }^{\circ} \mathrm{C}$ and load bearing capacity is reduced for $475^{\circ} \mathrm{C}$.

Fig. 3 presents the box diagram obtained from statistical analysis of maximum pull-out force for increasing exposure temperatures. Box plots are drawn in black and mean value with standard deviation in grey lines with markers. In each box, the mid-line shows the median value or 50th percentile, the top and bottom lines show the 75th and 25th percentiles and the whiskers show extreme values. The box width does not represent any aspect of the data.

\subsubsection{Steel fibers tension tests}

Fig. 4 shows the residual tension stress-strain curves obtained for the fibers previously exposed to $20^{\circ} \mathrm{C}, 300{ }^{\circ} \mathrm{C}, 375^{\circ} \mathrm{C}$ and $475{ }^{\circ} \mathrm{C}$. A reduction of fiber tensile strength and a change of shape of the stress-strain curve were observed only for the highest temperature. For this temperature, the peak stress occurs for a lower strain and it is followed by a nearly linear softening branch. Similar results were obtained by Abdallah et al. [40] who found that the steel fibers stress-strain behavior remained almost unchanged up to $200{ }^{\circ} \mathrm{C}$. The strength was practically unchanged but the stiffness and overall shape of the stress-strain response changed between $300{ }^{\circ} \mathrm{C}$ and $400{ }^{\circ} \mathrm{C}$. The strength greatly decreased and the shape of the stress-strain response significantly changed for higher temperatures [40]. Fig. 5 shows the maximum fiber tensile strength for all temperatures. It can be concluded that, for this type of fibers, tensile strength decreases at $475^{\circ} \mathrm{C}$.

The heated fibers also exhibited a change of color, they go from gray to golden/blue, then to dark gray and finally to rusted with increasing temperature. Abdallah, et al. [40] also observed a change of color and corroded surface due to oxidation over 400 ${ }^{\circ} \mathrm{C}$, while Beglarigale, et al. [24] and Caverzan et al. [31] noticed the formation of an oxide film covering the fibers surface for temperatures greater than $600{ }^{\circ} \mathrm{C}$.

\subsubsection{Compression tests}

Fig. 6 presents the average stress-strain curves obtained from compression tests of the different mixes after the exposure to high temperatures. Fig. 7 presents the analysis of compressive strength showing that dispersion is uniform for all materials and temperatures except for HSC at $375^{\circ} \mathrm{C}$ that has the greatest dispersion. Fig. 8 shows the static elastic modulus box plot; the values for all temperatures have similar dispersion and symmetry with the exception of HSC at $375^{\circ} \mathrm{C}$.

From the engineering point of view, there is practically no difference between HSC and SFRHSC compressive strength at room temperature. A slight contribution of fibers to elastic modulus (less than 6\%) and to compressive strength (less than 7\%) at room temperature is observed for the fiber contents analyzed. In contrast, it is well known that the ductility of post peak compression behavior is incremented by the fibers. The fibers delay the starting of crack growth at the matrix and extend the period of crack propagation, leading to a more ductile failure [23]. Moreover, the compressive strength can be incremented for higher fiber contents [46].

When concrete is exposed to high temperature a reduction in strength and stiffness can be observed. When increasing temperature from 20 to $300^{\circ} \mathrm{C}$ the differences are almost negligible. After $375^{\circ} \mathrm{C}$ the strength and the elasticity modulus clearly decrease, being more marked the decreases for $475^{\circ} \mathrm{C}$. The reductions in strength and stiffness due to high temperatures are in accordance with the behavior observed by other authors [21,23,22,47-49,27].

In coincidence with the results reported by Giaccio et al. [23], the elastic modulus is more affected than the compressive strength and the compressive behavior of FRC exposed to high temperature is similar to that of plain concrete but the addition of fibers leads to a slight increase of compressive strength and of the onset of cracks initiation. As expected, the results in Figs. 6-8 are different from those obtained for FRC tested at high temperatures, where there was a greater reduction of compressive strength, similar to the reduction of the modulus of elasticity [18].
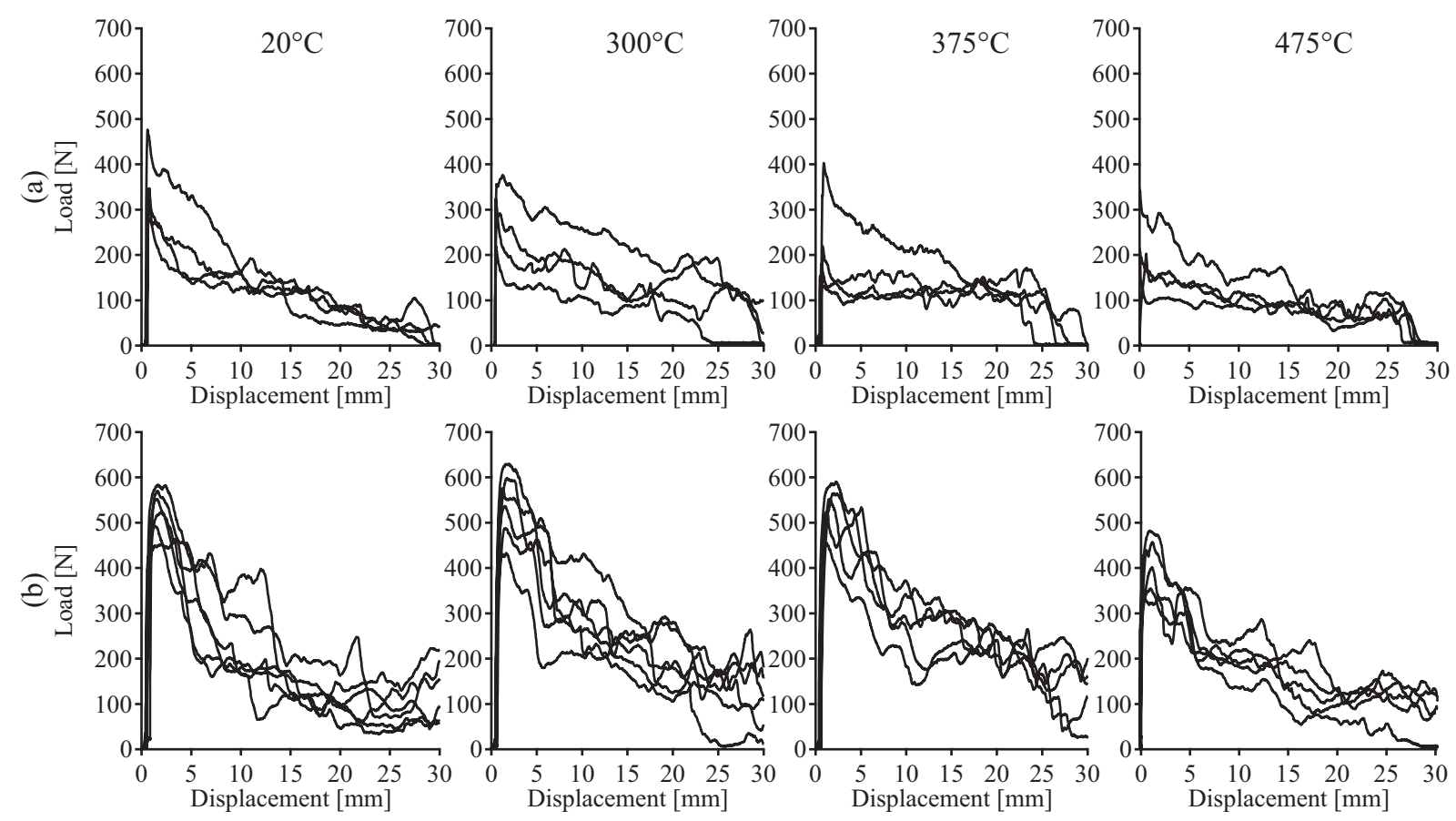

Fig. 2. Pull-out tests (a) Straight fibers (b) Hooked end fibers. 


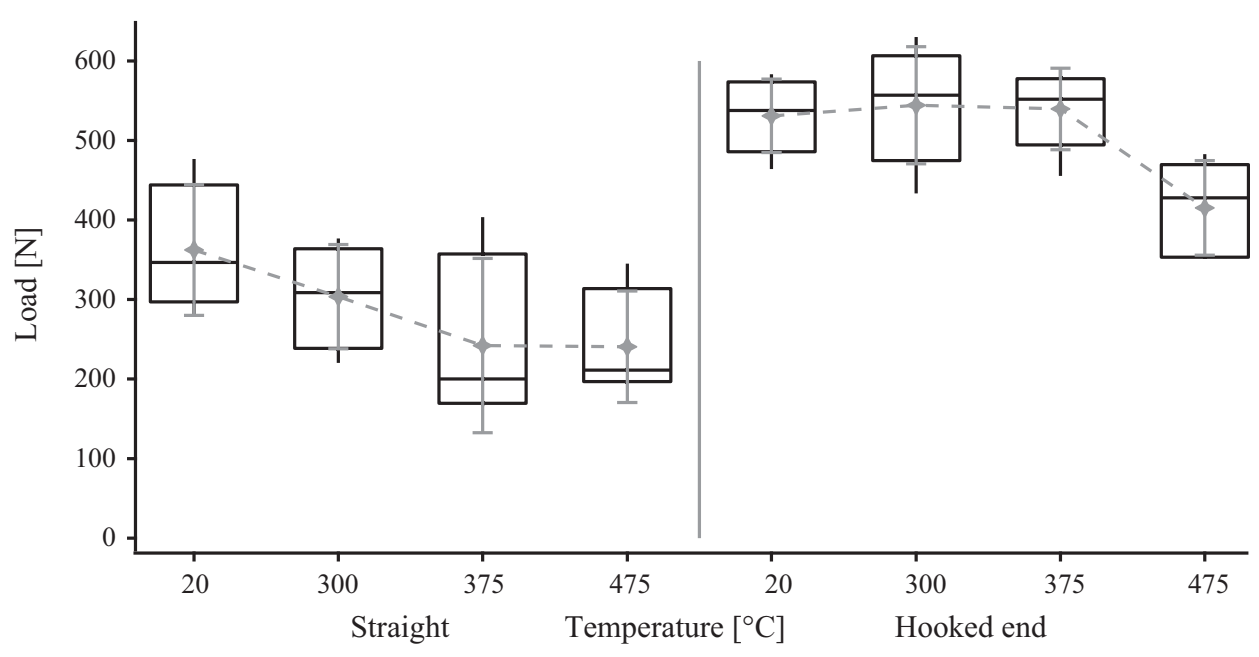

Fig. 3. Maximum pull-out load measured for straight and hooked end fibers.

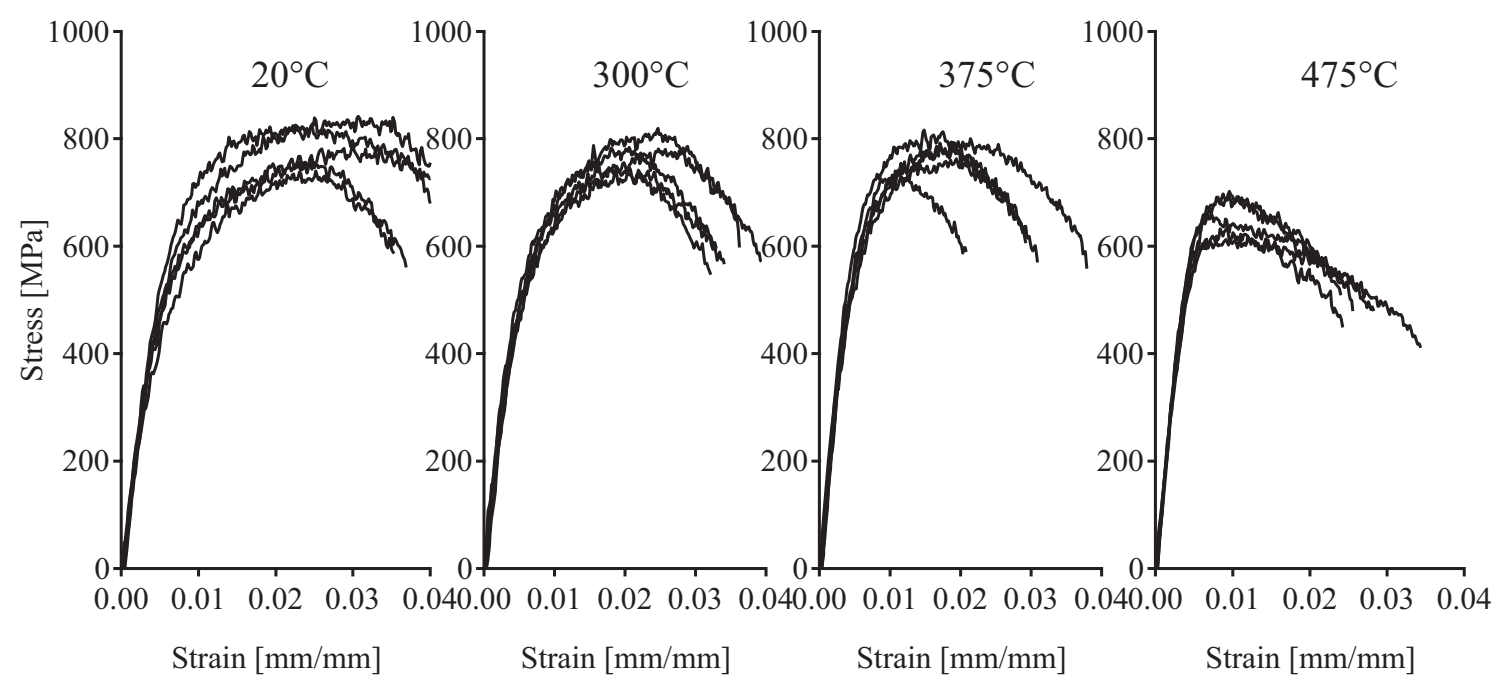

Fig. 4. Steel fibers tension tests.

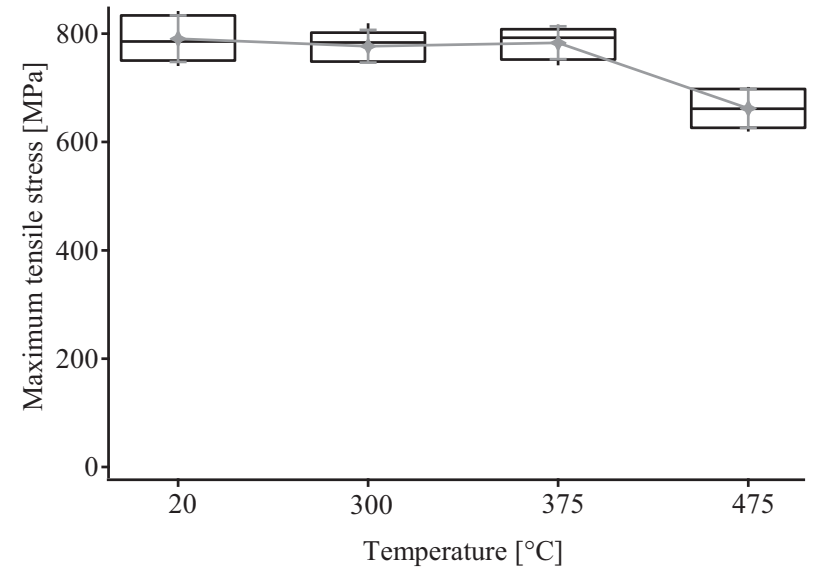

Fig. 5. Effect of temperature on residual fiber tensile strength.

\subsubsection{Ultrasonic pulse velocity tests}

The Ultrasonic Pulse Velocity represents a useful tool for evaluating the damage level in concrete internal structure. For that reason, the UPV was measured before and after heating the prisms that were going to be tested under flexure. Fig. 9 shows the variation of UPV as a function of the maximum temperature.

UPV mainly decreases after $300^{\circ} \mathrm{C}$; while the decreases in group $300{ }^{\circ} \mathrm{C}$ are near to $8 \%$, reductions in UPV for $375^{\circ} \mathrm{C}$ and $475{ }^{\circ} \mathrm{C}$ are in the order of 28 and $38 \%$ respectively. The addition of fibers causes an almost imperceptible reduction in the level of damage produced by temperature. Like in Ref. [23] Dynamic Elastic Moduli estimated from the UPV tests are consistent with the measurements of Static Elastic Modulus from compression tests.

\subsubsection{Bending tests}

Fig. 10 shows the Load-CMOD curves obtained from flexure tests for the different fiber dosages (HSC, SFRHSC30 and SFRHSC60) and temperatures. The number of fibers crossing the central section is also reported in the figures legend. Since relatively long fibers were used, most fibers were oriented in beams axial direction. While for HSC the load bearing capacity presents an abrupt decay after the peak, SFRHSC beams maintain load after the peak. The post-peak behavior depends on the fiber content and especially on the number of fibers across the central section. While SFRHSC30 beams present softening after the first peak load, for SFRHSC60 beams the residual capacity remains almost constant 


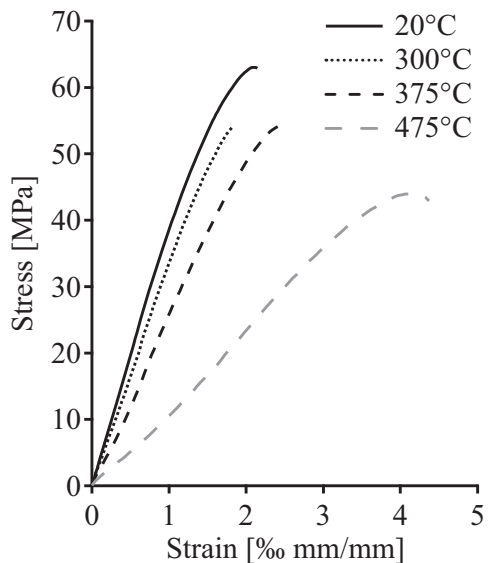

HSC

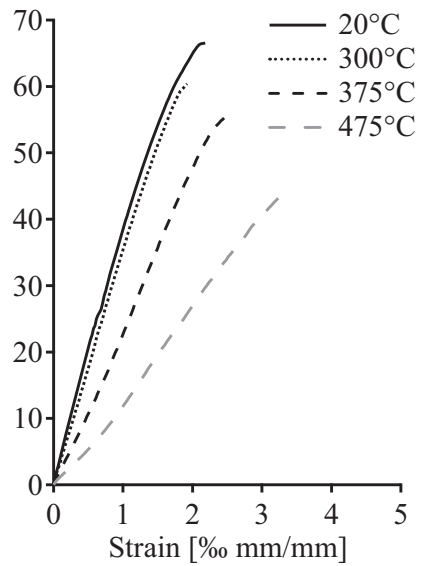

SFRHSC30

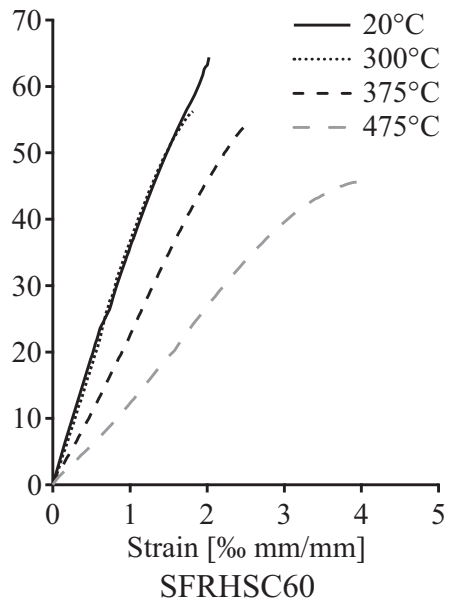

SFRHSC60

Fig. 6. Compression stress-strain curves.

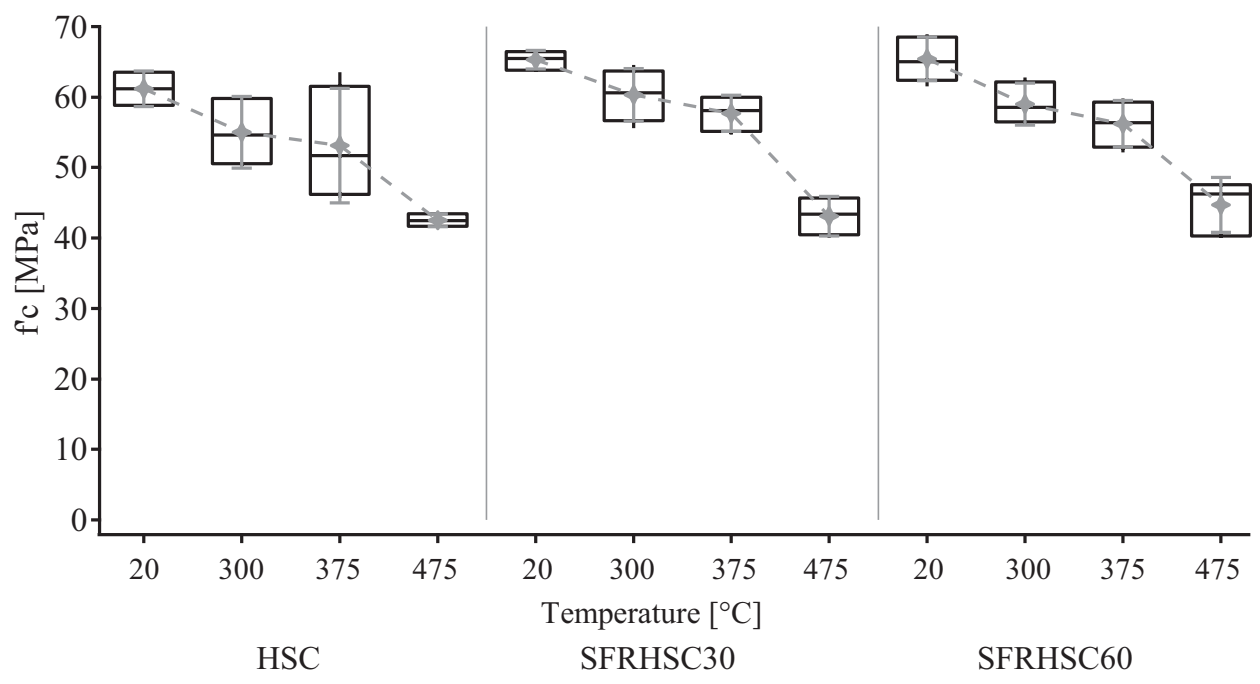

Fig. 7. Compressive strength.

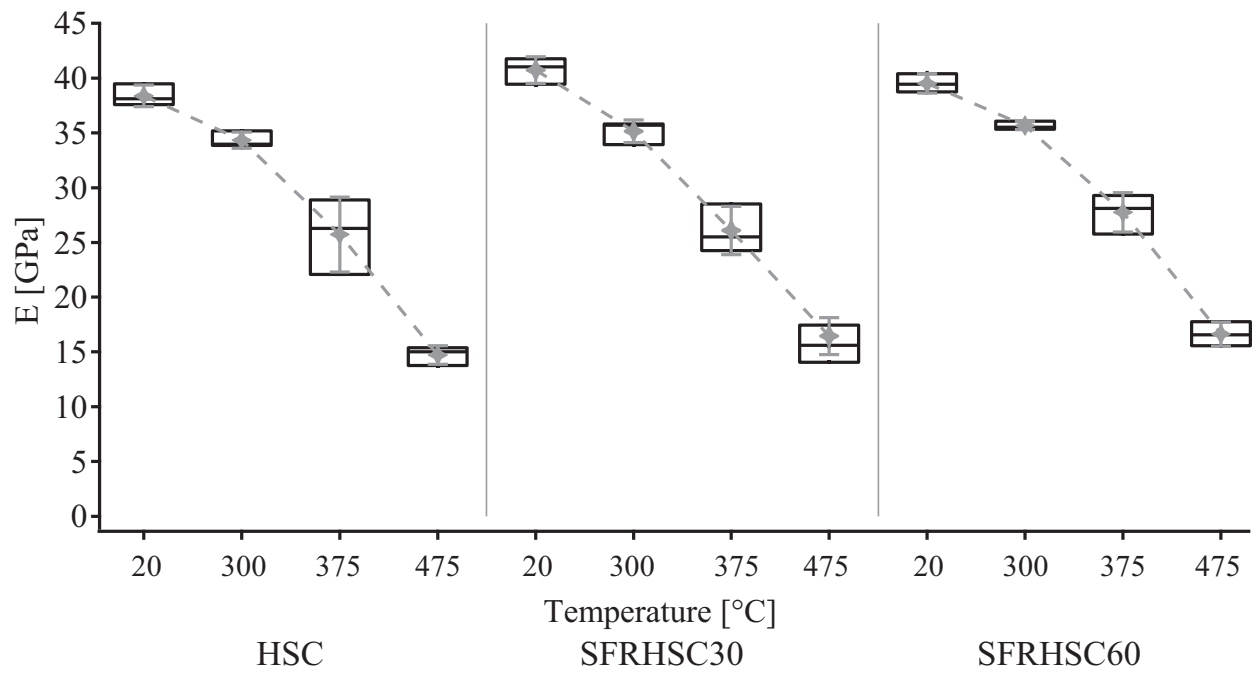

Fig. 8. Static elastic modulus. 


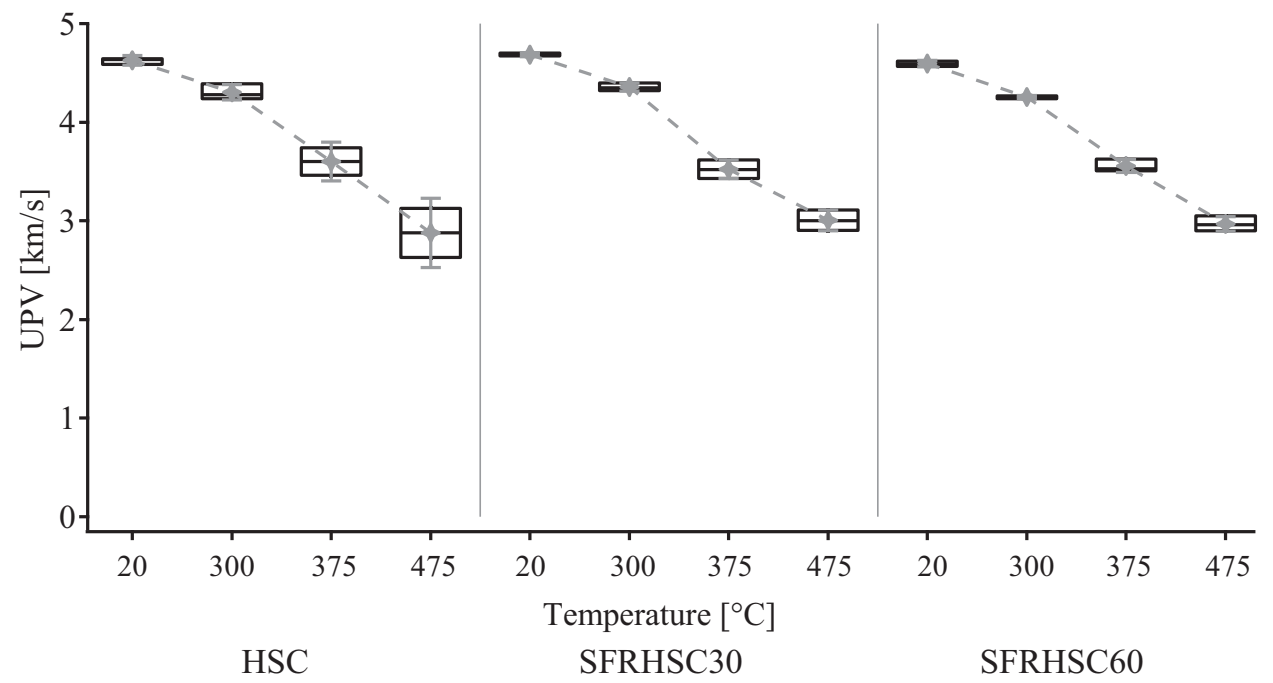

Fig. 9. Ultrasonic pulse velocity.
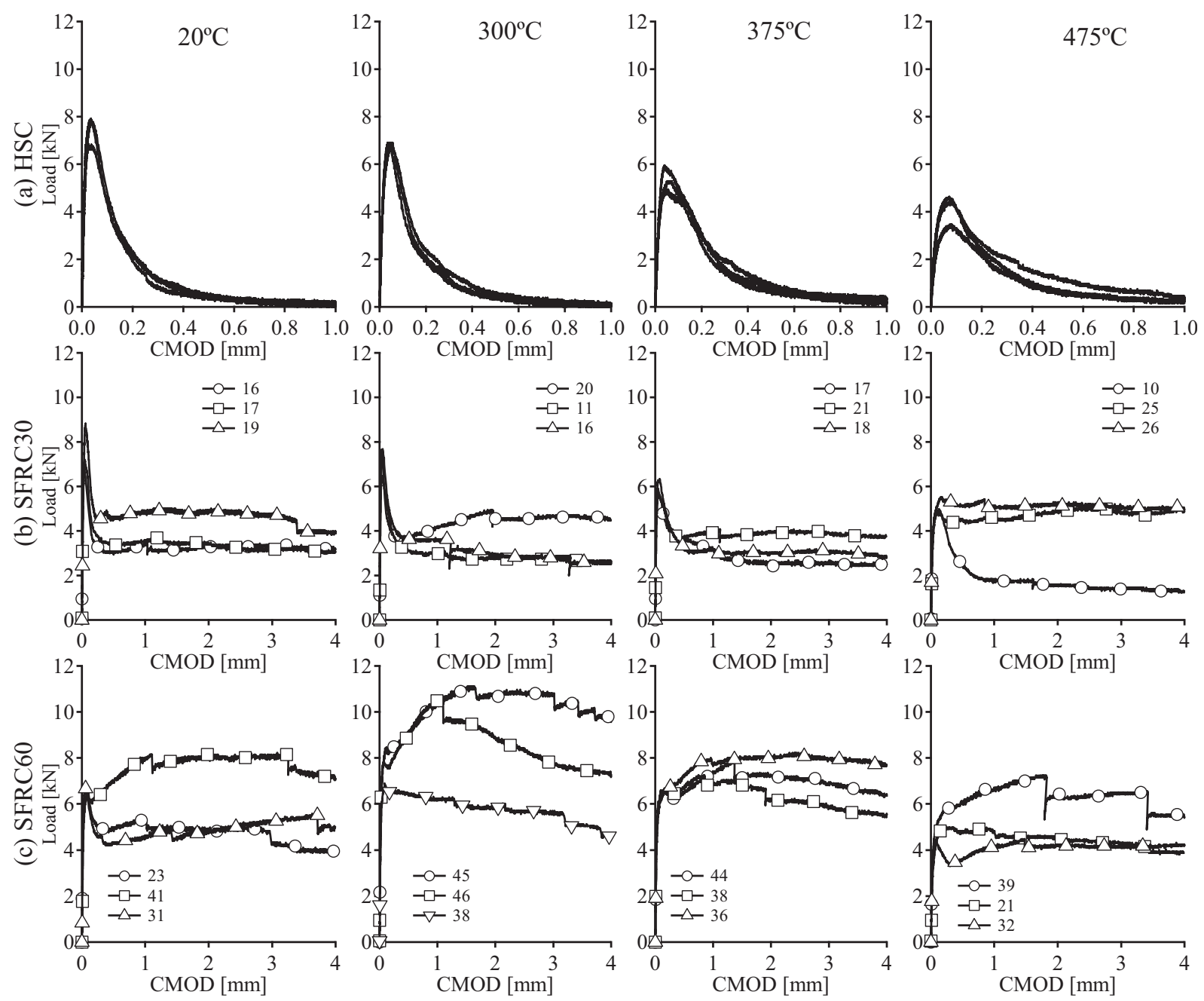

Fig. 10. Results from flexure tests. (a) HSC (b) SFRHSC30 (c) SFRHSC60

and some prisms even exhibit hardening. The dispersion in flexure response observed in Fig. 10 can be attributed to differences in the fiber contents at the fracture surfaces.

Fig. 11 presents the box plot for fiber density at the fracture surfaces of the prisms of SFRHSC30 and SFRHSC60 exposed to different temperatures. The boxes on the right correspond to the fiber content of all SFRHSC30 and SFRHSC60 beams. As expected, SFRHSC60 doubles SFRHSC30 fibers content but dispersion also increases. All groups corresponding to SFRHSC60 present greater dispersion in the number of fibers crossing the fracture surfaces. 


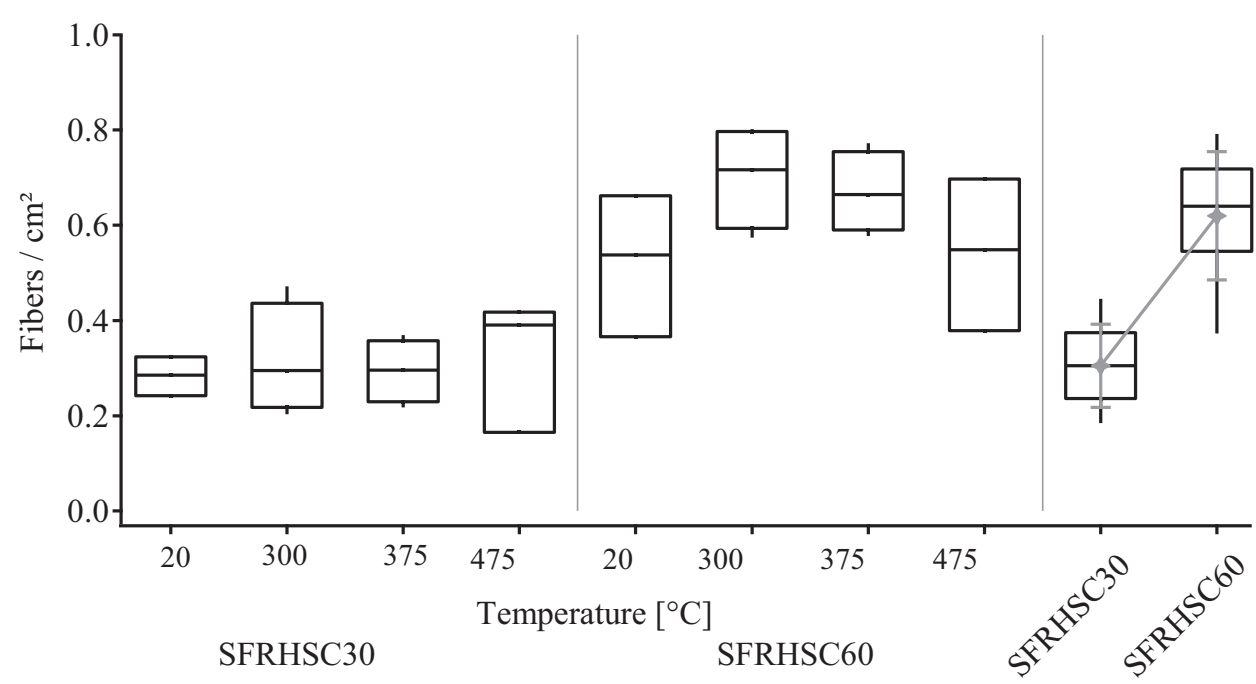

Fig. 11. Fiber density at the fracture surfaces.

Fig. 10 also shows that after temperature exposure, the peak load and the slope of the softening branch of HSC beams decrease. In the case of SFRHSC30, as the thermal damage increases, the differences between first peak load and residual capacity decrease, particularly for $475^{\circ} \mathrm{C}$. In the case of SFRHSC60, the first peak load decreases but the residual loading capacity remains almost constant up to $375^{\circ} \mathrm{C}$. For $475^{\circ} \mathrm{C}$ both peak load and residual load decrease.

The variation of $f_{\mathrm{L}}, f_{\mathrm{p}}, f_{\mathrm{R} 1}$ and $f_{\mathrm{R} 3}$ with temperature is presented in Figs. $12-15$. As expected, $f_{\mathrm{L}}$ and $f_{\mathrm{p}}$ are equal or almost equal in undamaged concrete $\left(20^{\circ} \mathrm{C}\right)$; the differences between these stresses increase as the internal damage increases. However, it can be seen that both parameters, representative of the matrix strength, decrease as the temperature increases, mainly over $300^{\circ} \mathrm{C}$. On the contrary, the residual stresses $f_{\mathrm{R} 1}$ and $f_{\mathrm{R} 3}$ appear to be less affected by high temperatures.

These flexure results are in accordance to those obtained by Giaccio et al. [23] who observed that the reductions in flexural strength are lower in FRC than in plain concrete, and that the post-peak strength is less affected than first crack strength, showing the effect of fiber reinforcement.
Fig. 16 shows the variation of the fracture energy with temperature. Although the residual matrix strength decreases with temperature increase, the fracture energy does not decrease with temperature and a slight increase is observed, both in plain and in SFRHSC. Fracture energy of concrete subjected to high temperature remains constant or increases [50,51] due to the more tortuous [52] and larger cracking path around aggregates that leads to a less severe strength lose [53].

\subsection{Discussion}

Fig. 17 shows the effect of high temperatures on HSC and SFRHSC compressive strength $\left(f_{c}^{\prime}\right)$, static and dynamic modulus of elasticity $\left(E, E_{d y n}\right)$ and the limit of proportionality obtained in bending tests $\left(f_{L}\right)$ expressed as relative values of the parameters corresponding to each material at $20^{\circ} \mathrm{C}$. The most affected property is stiffness. The elastic modulus abruptly decreases over $300{ }^{\circ} \mathrm{C}$ and for $475^{\circ} \mathrm{C}$ it is below $40 \%$ of that corresponding to the reference $\left(20^{\circ} \mathrm{C}\right)$. Compressive strength greatly decreases over $375^{\circ} \mathrm{C}$ being below $70 \%$ of room temperature value for $475^{\circ} \mathrm{C}$.

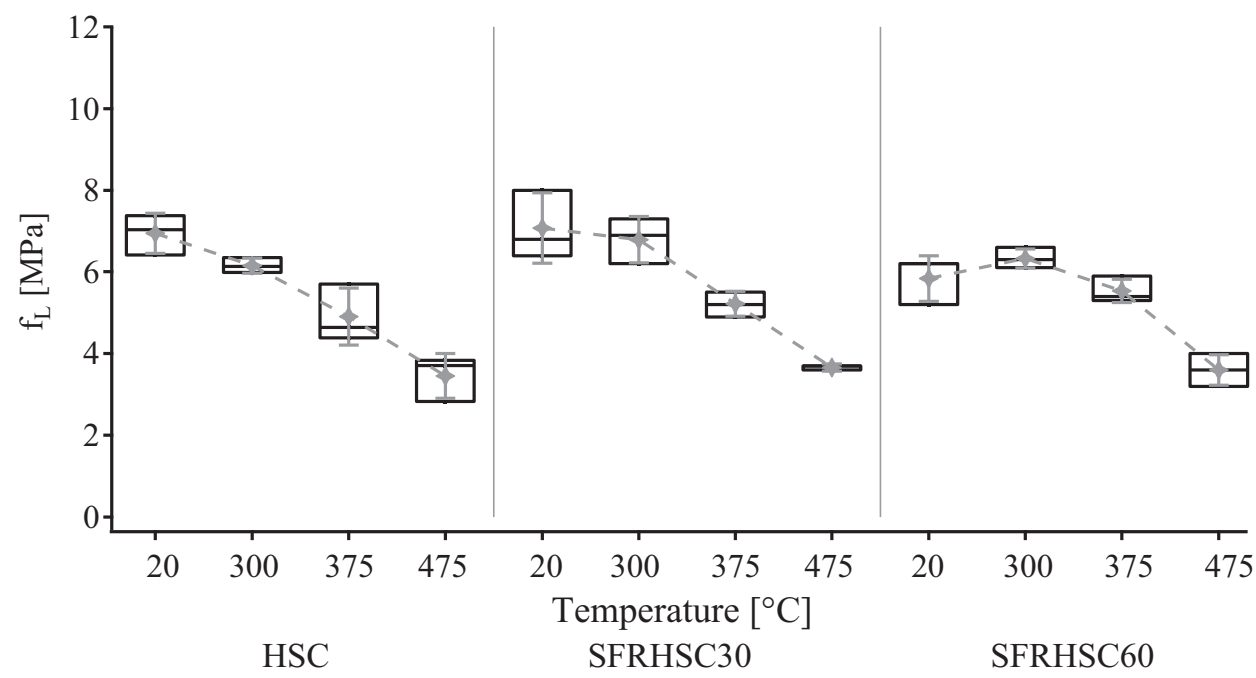

Fig. 12. Effect of temperature on limit of proportionality stress $f_{L}$. 


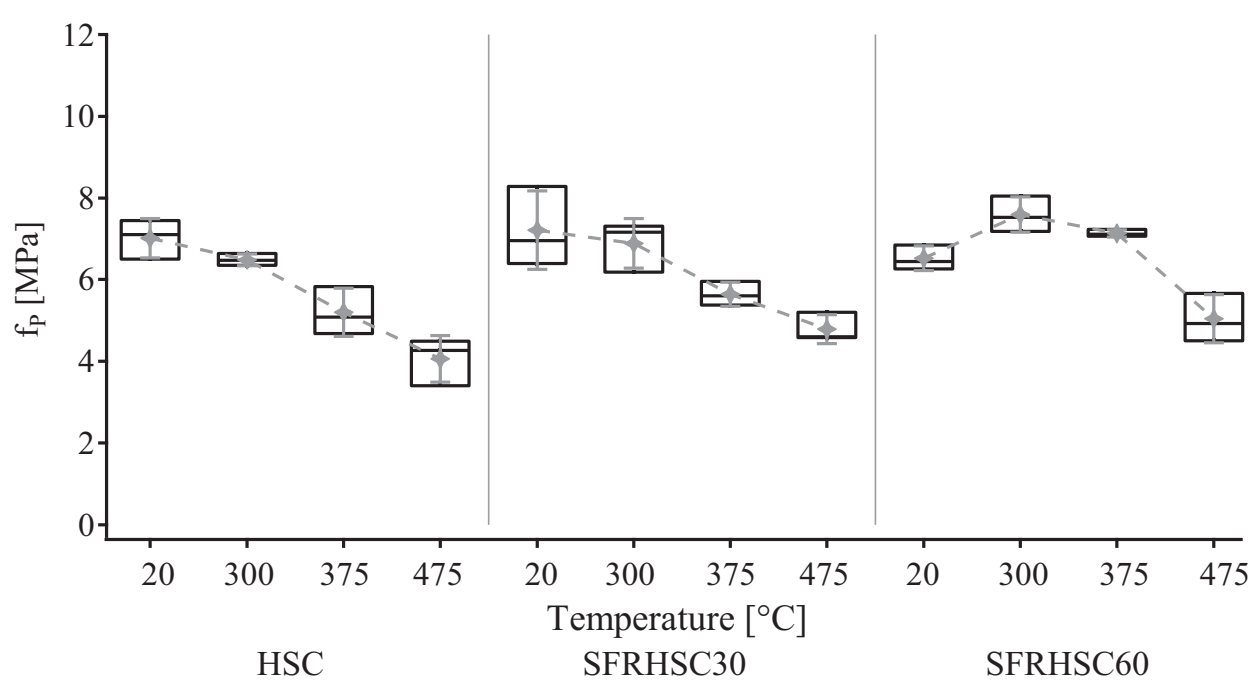

Fig. 13. Effect of temperature on first peak stress $f_{p}$.

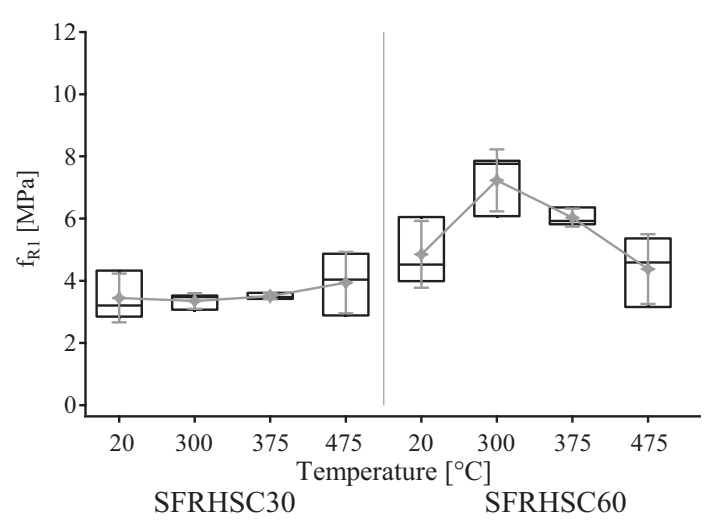

Fig. 14. Effect of temperature on $f_{R 1}$ residual strength.

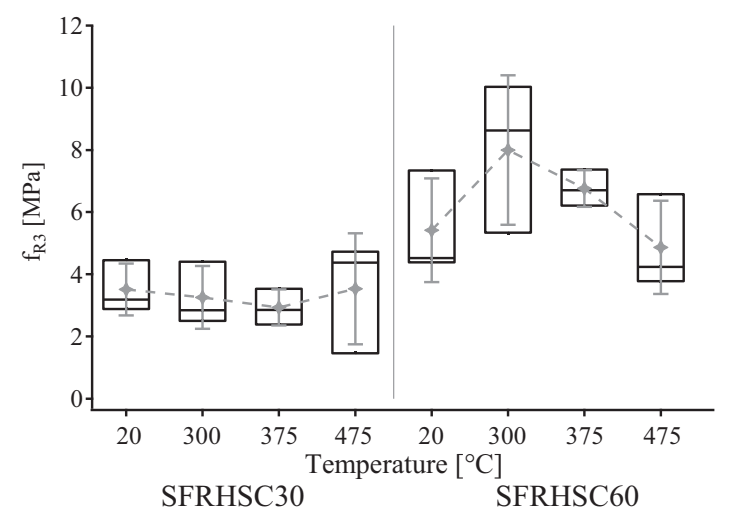

Fig. 15. Effect of temperature on $f_{R 3}$ residual strength.

The variation of the pull-out strength of straight and hooked end fibers with temperature is also plotted on Fig. 17a for comparison. Although the dispersion in experimental results is high, the average pull-out strength of straight fibers decreases with temperature. In this case pull-out strength is provided by adhesion and friction once the fiber is debonded. The reductions of both adhesion and friction are mainly produced by matrix microcracking and also by some fiber surface damage, due to the exposition to high temperatures.

In accordance to the results obtained by other authors, the decrease of the pull-out strength of hooked end fibers is in the same order [30] but lower than that of concrete compressive strength decrease [39] and significantly less than that of concrete tensile strength. However, while concrete compressive strength decreases from $300^{\circ} \mathrm{C}$, the decrease of pull-out strength of hooked end fibers begins for higher temperatures. Hooked end steel fiber pull-out mechanism is less sensitive to high temperatures than straight fibers pull-out mechanism. In the case of hooked end fibers, the pull-out load is beared by adhesion and anchorage effects. However, the contribution of adhesion is lower than anchorage effect provided by the hook. Anchorage effect begins with the deformation of the matrix surrounding the hook and continues until the fiber yield strength is reached. When the fiber is straightened, the pull-out resistance is provided by frictional effects [54]. Anchorage effect depends on matrix strength and fiber yielding strength that are both affected by the exposure to high temperature.

These pull-out tests results are in accordance to the results obtained by Abdallah et al. [40] who showed that the pull-out behavior of straight fibers was significantly influenced by heating while the behavior of hooked end fiber did not vary significantly in the range $20-400{ }^{\circ} \mathrm{C}$ but was dramatically affected for greater temperatures. They also found that the reduction in bond strength at elevated temperatures was strongly related to the degradation of the constituent materials properties.

It was observed that the difference between the peak flexure load and the residual flexure capacity decreases with temperature (see Fig. 10). Taking into account that the first peak flexure load is related to HSC flexure strength, while the residual strength is related to pull-out mechanism, the obtained results are in agreement with the observed pull-out behavior that was less affected by the exposure to high temperature than HSC flexure strength.

It is widely recognized that fiber distribution represents a key variable in the response of SFRHSC, particularly in the post peak loading capacity. As a consequence, the density of fibers at the fracture surface appears as one of the principal reasons for the variability of the post peak response of SFRHSC. Then, to discuss the effect of temperature on bending tests, Fig. 18 represents the variation of the individual characteristic parameters obtained with the density of fibers measured at the fracture surface. The results of $f_{\mathrm{L}}, f_{\mathrm{P},}, f_{\mathrm{R} 1}, f_{\mathrm{R} 3}$ 


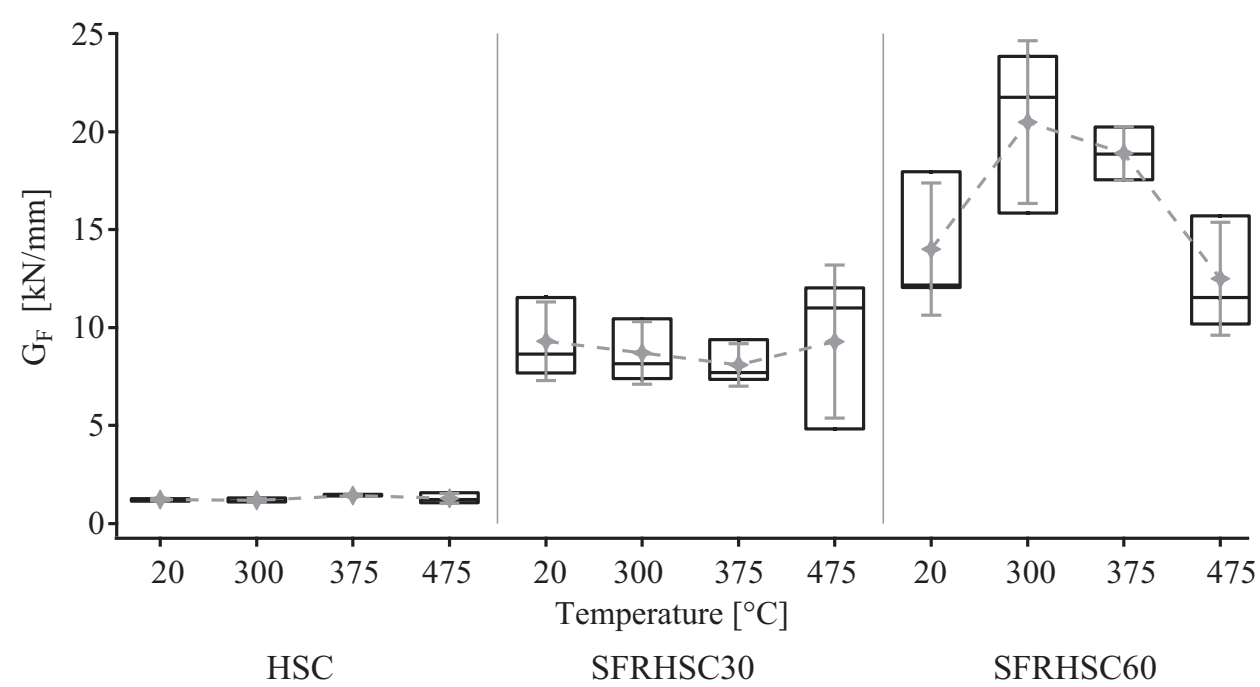

Fig. 16. Effect of temperature on fracture energy.

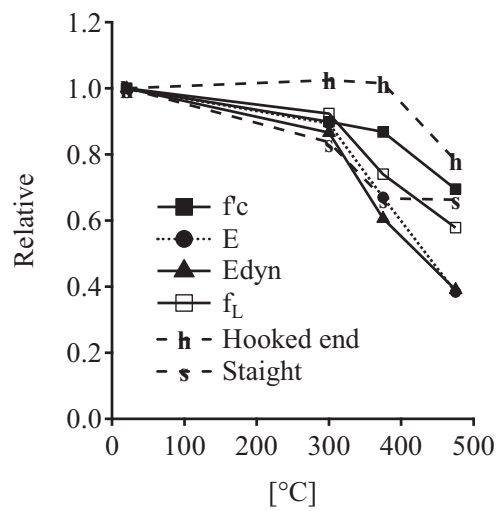

(a) HSC

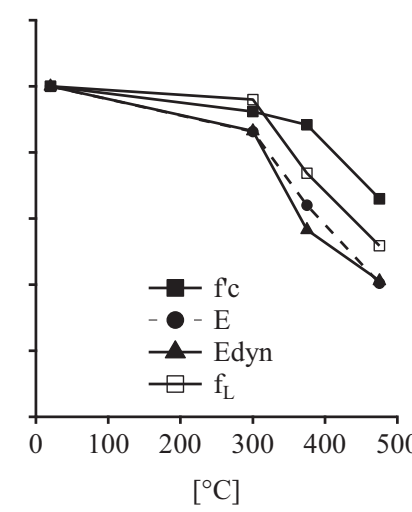

(b) SFRHSC30

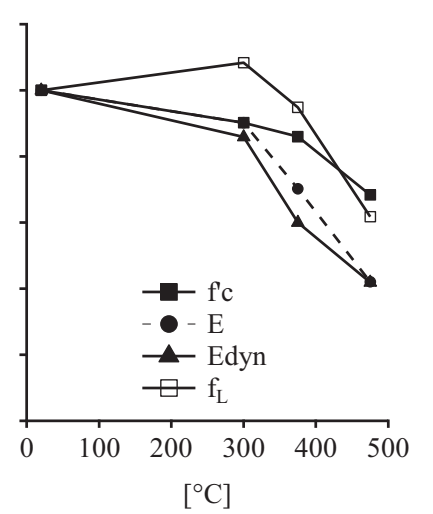

(c) SFRHSC60

Fig. 17. Relative values for concrete mechanical properties.

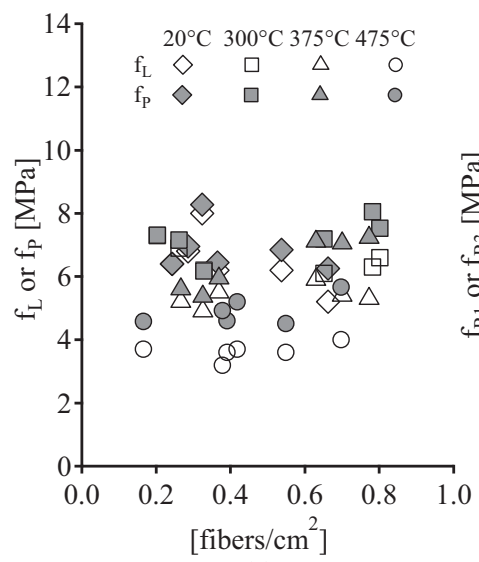

(a)

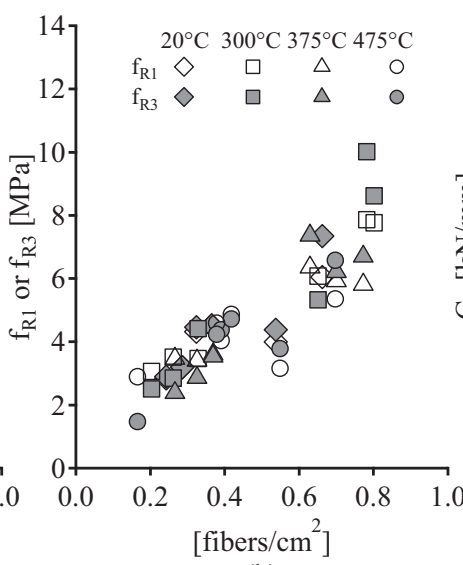

(b)

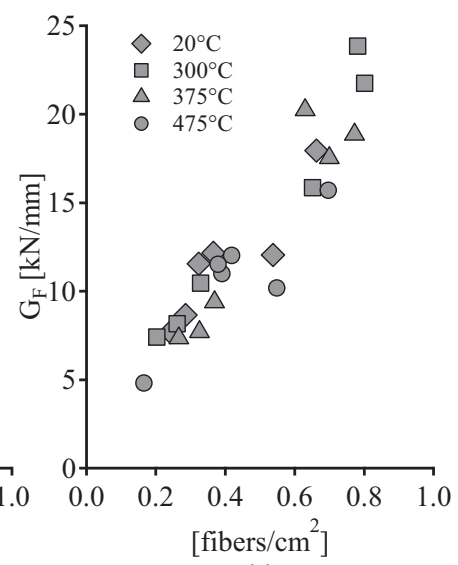

(c)

Fig. 18. Effect of fibers density on the mechanical parameters measured in bending.

and $\mathrm{G}_{\mathrm{F}}$, differentiating the values corresponding to each temperature are included.

As expected, $f_{\mathrm{P}}$ is greater than or equal to $f_{\mathrm{L}}$; the major differences correspond to the damaged concretes and increase with temperature increase and the incorporation of fibers. The values of $f_{\mathrm{L}}$ and $f_{\mathrm{P}}$ do not vary with the fiber density and are practically constant for SFRHSC30 and SFRHSC60 exposed to temperatures lower or equal to $375^{\circ} \mathrm{C}$, being clearly smaller for $475^{\circ} \mathrm{C}$. Both parameters mainly depend on the matrix strength. In damaged concrete it seems more significant to evaluate the matrix strength in terms 
of $f_{\mathrm{P}}$ due to the premature non-linearity that is observed in the tension stress - CMOD behavior. In the case of the post-peak behavior, it is observed that both $f_{\mathrm{R} 1}$ and $f_{\mathrm{R} 3}$ vary directly with the density of fibers. Temperature slightly affects the residual capacity for a certain fiber density. It is important to emphasize that although high temperature affects the matrix and can affect the pre-cracking behavior of the SFRHSC, the cracked SFRHSC preserves an important load capacity, even having been exposed to high temperature.

The differences in $G_{F}$ for SFRHSCs of the same group (same nominal fiber content and same temperature) are mainly due to the variability in fiber density. (Fig. 18c) However, there is a slight reduction of fracture energy with temperature being more marked for the $475{ }^{\circ} \mathrm{C}$ group (circles).

Finally, it must be mentioned that the service life of SFRHSC structures is expected to be longer than that of HSC structures since SFRHSC conserves its residual mechanical properties and crack control capacity even if it is exposed to high temperatures.

\section{Numerical analysis}

The pull-out behavior of steel fibers exposed to high temperatures and its effect on the residual mechanical performance of SFRHSC is numerically analyzed in this section. A pull-out model [55] and a meso-model developed for SFRC [4] are used for this purpose. The numerical analysis is useful to assess how high temperature affects the different phenomena defining the fibers extraction from the matrix and their effect on the fibers pull-out curve and on SFRHSC residual mechanical behavior. In this way, the numerical results can help understanding the experimental results and confirming the conclusions. Moreover, this model can be used to design the composite and to optimize the fiber type and content in order to get higher mechanical and thermal performance with lower cost.

In the case of hooked end fibers, like those analyzed in this paper, pull-out strength is provided by adherence and frictional forces developed at the fiber/matrix interface and by the anchorage effect provided by the hook. The model used to simulate the pullout response is based on the approach proposed by Chanvillard [56]. The pull-out load $P$ can be obtained from the virtual power principle and can be calculated as follows [55]:

$P=\left\{1-\frac{2 f \operatorname{sen}(\hat{\varphi} / 2)}{1+f \operatorname{tg}(\hat{\varphi} / 2)}\right\}^{-1} \int_{0}^{L_{f m}}\left(\frac{d C}{d \delta} M+t_{f m}\right) d s$

where $M$ is the moment in the fiber, $\delta$ is the displacement of the fiber free end, $C$ is the fiber curvature, $L_{f m}$ is the fiber embeded length, $s$ is a curvilinear coordinate along the fiber axis, $t_{f m}$ is the tangential force resultant at the interface, $f$ is the frictional coefficient. $\hat{\varphi}$ is the angle corresponding to the change of inclination of the fiber outside the matrix, $\hat{\varphi}=0$ for aligned fibers that are normal to the crack surface. In the case of inclined fibers $\hat{\varphi} \neq 0$ and the embedded length is reduced as a consequence of the matrix rupture. The pull-out curve can be obtained integrating Eq. (1) for increasing displacements $\delta$ and can be used to simulate the evolution of the fibers inelastic threshold. It should be noted that the resulting pull-out curve depends not only on the fibers geometry, embedded length and inclination but also on the fibers material mechanical properties (i.e. elastic modulus and yield stress), the concrete strength and the fiber/matrix interface properties.

Modified mixture theory for orthotropic materials is used to simulate SFRHSC behavior taking into account the contribution of concrete and fibers. Particularly, the anisotropic behavior of fibers and their slipping are modeled in a simplified way [4].

SFRHSC is considered as a composite formed by a HSC matrix identified with HSC subscript and steel fibers oriented in $n$ directions that are identified with $F_{k}$ subscript. The fiber/matrix interface is not explicitly considered. Mixture theory compatibility condition is written as

$\left(\varepsilon_{i j}\right)_{S F R H S C}=\left(\varepsilon_{i j}\right)_{H S C}=\left(\varepsilon_{i j}\right)_{F k} \quad k=1, . ., n$

where $\varepsilon_{i j}$ are the strain tensors of the composite and the components.

The stress in the composite is obtained as

$\left(\sigma_{i j}\right)_{\text {SFRHSC }}=\frac{\partial \Psi\left(\varepsilon_{k l}, \alpha_{k}\right)}{\partial \varepsilon_{i j}}=\sum_{m=1}^{n+1} k_{m} \frac{\partial \Psi_{m}\left(\varepsilon_{k l},\left(\alpha_{i}\right)_{m}\right)}{\partial \varepsilon_{i j}}=\sum_{m=1}^{n+1} k_{m}\left(\sigma_{i j}\right)_{m}$

where $\Psi\left(\varepsilon_{i j}, \alpha_{i}\right)$ and $\Psi_{m}\left(\varepsilon_{i j},\left(\alpha_{i}\right)_{m}\right)$ are the free energy densities of the composite and each of the $m$ components respectively, $k_{m}=d V_{m} / d V$ is the volume ratio, $\left(\alpha_{i}\right)_{m}$ is a set of internal variables and $\left(\sigma_{i j}\right)_{m}$ is the stress in the $m$ component that is obtained from the corresponding constitutive equation.

The fibers constitutive model is modified to allow fiber sliding without explicitly modelling the fiber/matrix interface. The fibers total strain is supposed to represent both the fibers and the interface strains and to be formed by an elastic strain $\left(\varepsilon_{i j}^{e}\right)_{F k}$, a plastic strain $\left(\varepsilon_{i j}^{p}\right)_{F k}$ and a slipping strain $\left(\varepsilon_{i j}^{S}\right)_{F k}$.

$\left(\varepsilon_{i j}\right)_{F k}=\left(\varepsilon_{i j}^{e}\right)_{F k}+\left(\varepsilon_{i j}^{p}\right)_{F k}+\left(\varepsilon_{i j}^{S}\right)_{F k} ; \quad k=1,2, \ldots, n$

Only the first two terms (elastic and plastic) strictly take place in the fibers, the third term corresponds to the inelastic fiber-matrix relative displacement that takes place at the interface during the pull-out process [55,57]. As a result, the strain in the fibers is not actually equal to that in the matrix. Plastic deformation together with fiber matrix sliding are modeled with an orthotropic elastoplastic model. The inelastic threshold in fibers axis direction represents the slipping threshold that is usually smaller than the yielding threshold. Fibers axial hardening can be obtained from pull-out tests or from a meso-mechanical model [55] like that previously described. Modified plastic damage model is used for concrete [49].

\subsection{Fibers pull-out simulation}

First, in order to calibrate the fibers pull-out properties at room temperature and their variation with temperature, the fibers pullout tests are numerically simulated. The material properties used for these simulations are presented in Table 2. The fibers and the matrix parameters and their variation with temperature were measured in the tests, see Figs. 4-8. The variation of the interface properties with temperature can be indirectly obtained calibrating the numerical pull-out response of straight fibers exposed to different temperatures with experimental results presented in Fig. $2 \mathrm{a}$.

The pull-out curves for straight and hooked end fibers numerically obtained are presented in Fig. 19 where average experimental results are included for comparison. It should be observed that a good agreement between numerical and experimental results is obtained for hooked end fibers using the parameters measured in the straight fibers tests. The pull-out response for different fibers inclinations and embedded lengths can be obtained with the pull-out model used in this paper [55] that takes into account the fibers inclination and the embedded length.

The interface parameters indirectly obtained from calibration of experimental results and presented in Table 2 show the effect of temperature on adhesion and friction. It can be observed that the reduction with temperature of the maximum tangential strength is in the order of the reduction of concrete flexure strength and greater than those of the residual tangential stress and friction coefficient that are in the order of the reduction of concrete compressive strength. 
Table 2

Pull-out parameters used for numerical simulations.

\begin{tabular}{|c|c|c|c|c|}
\hline & \multicolumn{4}{|c|}{ Temperature $\left[{ }^{\circ} \mathrm{C}\right]$} \\
\hline & 20 & 300 & 375 & 475 \\
\hline \multicolumn{5}{|l|}{ Fibers parameters } \\
\hline Yield stress $f_{y}\left[\mathrm{~N} / \mathrm{mm}^{2}\right]$ & 790 & 780 & 780 & 660 \\
\hline \multicolumn{5}{|l|}{ Matrix Parameters } \\
\hline \multicolumn{5}{|l|}{ Interface parameters } \\
\hline Maximum tangential stress $\tau_{\max }\left[\mathrm{N} / \mathrm{mm}^{2}\right]$ & 3.40 & 3.00 & 2.30 & 2.00 \\
\hline Residual tangential stress $\tau_{\text {resd }}\left[\mathrm{N} / \mathrm{mm}^{2}\right]$ & 2.50 & 2.50 & 2.00 & 1.70 \\
\hline Frictional coefficient $f$ & 0.10 & 0.10 & 0.09 & 0.07 \\
\hline
\end{tabular}
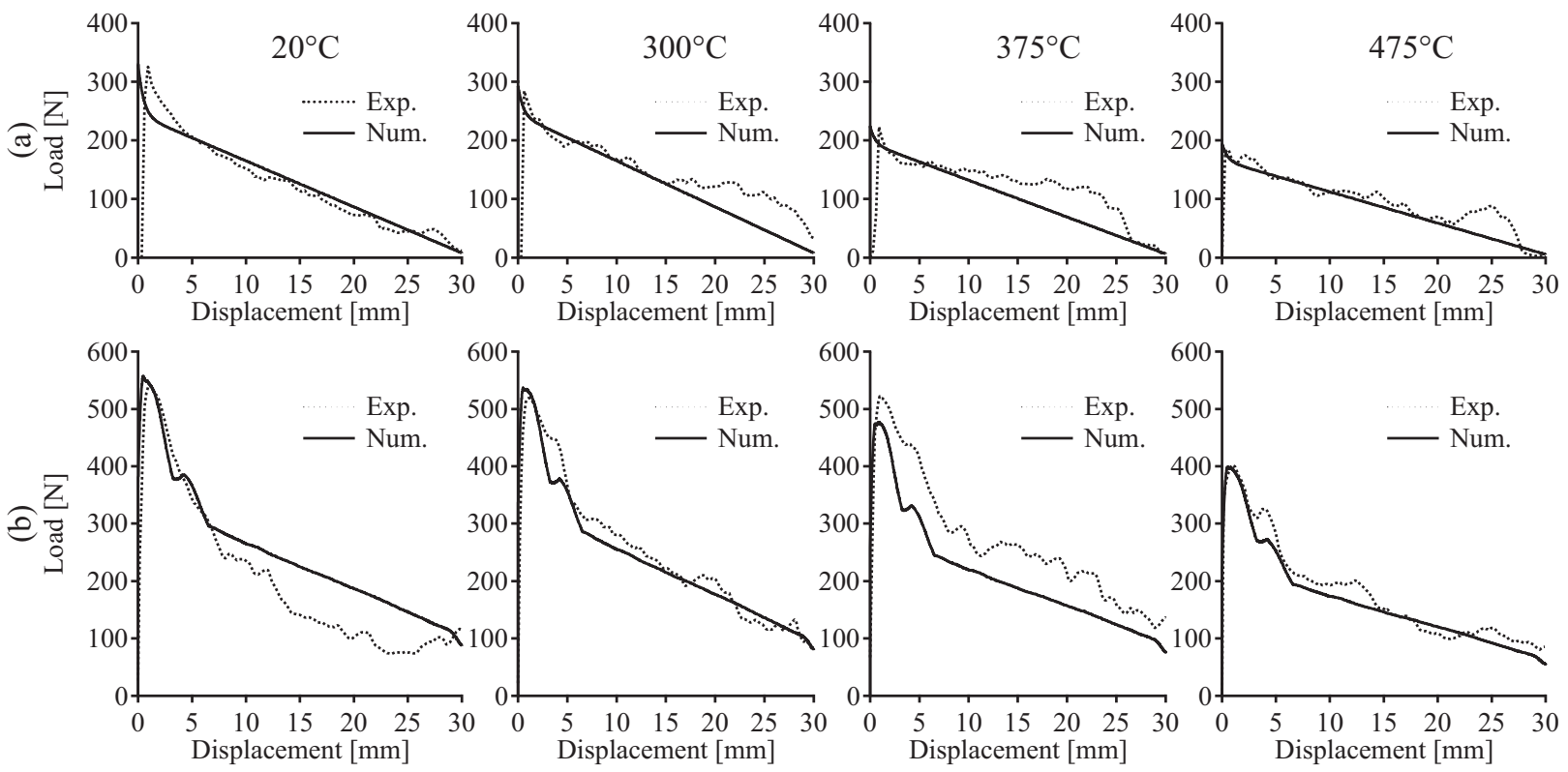

Fig. 19. Experimental and numerical results from pull-out tests. (a) straight fibers (b) hooked end fibers.

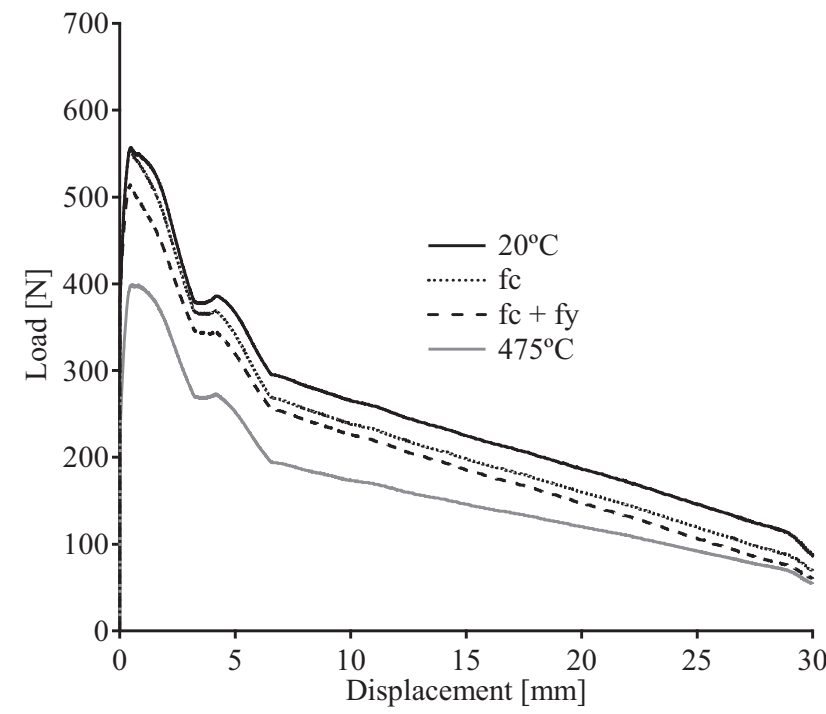

Fig. 20. Effect of the different material parameters on the pull-out behavior.

The additional contribution of the hooks to pull-out strength depends on the fibers and the matrix strength because the fibers should be plastically deformed to slide and the microcracking of

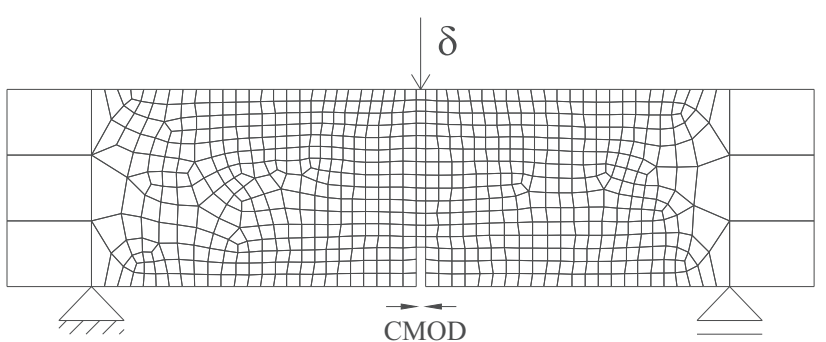

Fig. 21. Finite element mesh.

the concrete matrix facilitates the fiber sliding without the need of deforming the hook, since the walls of the fiber channel are less resistant. As shown in Table 2, concrete and fibers strength decreases due to temperature exposure and, as a consequence, the anchorage effect is also reduced.

Fig. 20 shows how the temperature degradation of the different mechanisms involved affect pull-out response of a hooked end fiber for the case of the maximum temperature studied $\left(475^{\circ} \mathrm{C}\right)$. The top curve corresponds to control material properties $\left(20^{\circ} \mathrm{C}\right)$, in the next curve only the degradation of concrete strength was considered, in the next curve the decrease of steel strength is added and finally the degradation of interface is added. Summarizing, the lowest curve represents the pull-out response considering 

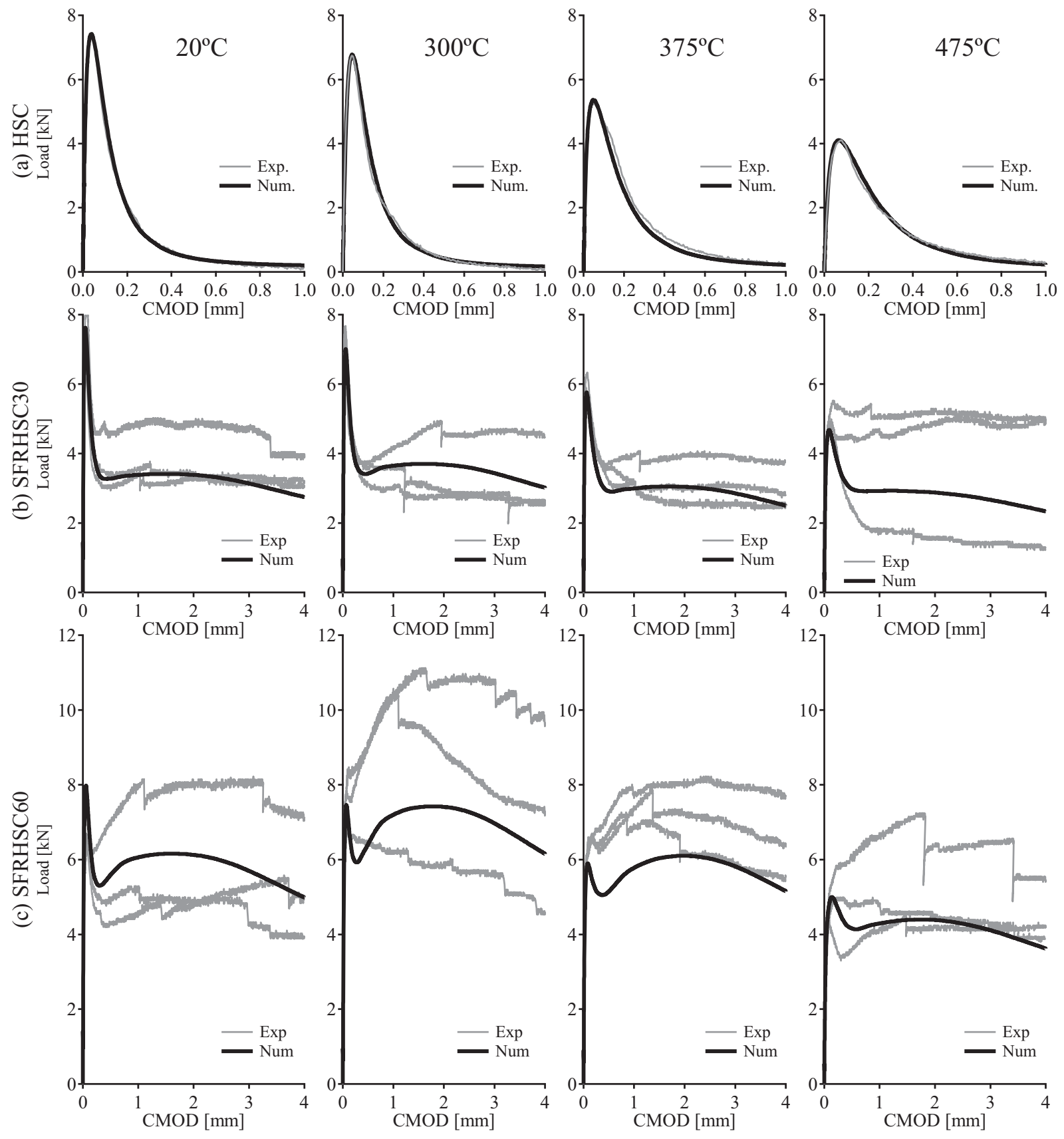

Fig. 22. Residual flexural response. (a) HSC (b) SFRHSC30 (c) SFRHSC60.

the effect of temperature $\left(475^{\circ} \mathrm{C}\right)$ on all the parameters affecting the pull-out mechanism. It can be observed that the thermal damage of concrete compressive strength shifts down the control curve, the thermal damage of steel strength reduces the first peak and shifts the previous curve and interface thermal damage is responsible for the mayor force reduction, especially up to $7 \mathrm{~mm}$ displacement.

\subsection{SFRHSC flexure response simulation}

The residual mechanical behavior of HSC and SFRHSC beams tested under three points flexure is simulated to show the effect of concrete, fibers and pull-out degradation on the SFRHSC flexure response. Some of the material properties like HSC compressive strength and elastic modulus at room temperature and for

Table 3

HSC tension properties.

\begin{tabular}{|c|c|c|c|c|}
\hline & \multicolumn{4}{|c|}{ Temperature $\left[{ }^{\circ} \mathrm{C}\right]$} \\
\hline & 20 & 300 & 375 & 475 \\
\hline Tension strength $f_{t}\left[\mathrm{~N} / \mathrm{mm}^{2}\right]$ & 4.41 & 4.40 & 2.95 & 2.30 \\
\hline Fracture energy $G_{F}\left[\mathrm{Nmm} / \mathrm{mm}^{2}\right]$ & 0.130 & 0.132 & 0.145 & 0.150 \\
\hline
\end{tabular}


different exposure temperatures can be directly obtained from the test results (see Figs. 7 and 8). Other parameters like HSC tensile strength and fracture energy at room temperature and for different exposure temperatures can be indirectly obtained calibrating the numerical model to reproduce the HSC beams behavior under flexion (see Table 3). Fig. 21 shows the finite element mesh used, the boundary conditions and the nodes where displacements were applied. Plain stress four nodes finite elements with four Gauss points were used. The load-CMOD curves numerically obtained for HSC beams at room temperature and for the beams previously exposed to different temperatures are compared with experimental average response in Fig. 22a.

With the pull-out curves modified by the effect of temperature exposure and the calibrated HSC properties, the residual mechanical behavior of the tested SFRHSC beams is numerically simulated. The average fiber density measured in the central section of each group of beams was used for the numerical simulations. The fibers survey in the central section after the tests showed the actual fibers orientation and an average embedded length of $1 / 3$ of the fiber length. The pull-out response for different fibers inclinations and that embedded length was obtained with the pull-out model [55] that takes into account the fibers inclination and the embedded length.

The finite element mesh used is the same shown in Fig. 21. Fig. 22b and c show the results of the numerical simulation vs. the tests results. In general, a good agreement between numerical and experimental results is obtained. The differences observed can be attributed to the distribution and orientation of the fibers in the beams that are responsible for the dispersion in experimental results, the simplifying assumptions and the average data used for the numerical models. Nevertheless, the model approximately reproduces the effect of high temperature on SFRHSC and it is useful to predict the residual flexure capacity taking into account the effect of temperature on the component materials and the pull-out mechanism.

\section{Concluding remarks}

The effect of high temperature exposure on steel fibers pull-out from a HSC matrix and how it affects the mechanical behavior of SFRHSC after the exposure to high temperature have been experimentally and numerically studied. The main findings are summarized as follows:

Pull-out strength both of straight and hooked end steel fibers decreases with temperature. Straight fibers pull-out strength reduction is due to the damage of the fiber/matrix interface that affects adherence and friction. The reduction of the parameters related to the interface strength is similar to that of the matrix flexure strength. In contrast, the reduction of pull-out strength of hooked end fibers is lower and starts for higher temperature than the reduction of the matrix compressive strength. In this case, the decrease in pull-out strength is partly due to the reduction of matrix compressive strength, partly due to the reduction of steel strength and partly due to the thermal damage of the interface.

The ability of FRC to preserve a significant part of its postpeak flexure strength capacity after exposure to high temperatures lower than $500{ }^{\circ} \mathrm{C}$ is in accordance to pull-out tests of single fibers, which indicate that in damaged concrete the reductions in fiber-matrix pull-out strength are significantly lower than the decreases measured on the matrix compressive strength.

The numerical model calibrated with the results of pull-out tests was able to reproduce the flexure behavior of SFRHSC beams previously damaged by high temperatures. It can be used as a design tool to predict the mechanical behavior of FRC elements that are expected to be exposed to high temperatures.

It should be noted that since relatively long fibers were used, for beams most fibers were oriented axially. However, the particular distribution of fibers obtained for these small beams does not invalidate the comparisons between beams subjected to different temperatures or the comparisons with numerical results presented in this paper for which the actual fiber content and orientation were considered.

\section{Acknowledgements}

The authors wish to thank Pablo Bossio and Anabela Gerez for the collaboration in the experimental campaign, Ms Amelia Campos for the English revision and the financial support of National Agency for Scientific and Technological Promotion PICT 2013 1740, National Scientific and Technological Research Council CONICET - PIP 0765, National University of Tucumán PIUNT 26E/520 and LEMIT-CIC.

\section{References}

[1] P. Bamonte, P.G. Gambarova, Properties of concrete subjected to extreme thermal conditions, J. Struct. Fire Eng. 5 (2014) 47-62.

[2] M.R. Bangi, T. Horiguchi, Pore pressure development in hybrid fibre-reinforced high strength concrete at elevated temperatures, Cem. Concr. Res. 41 (2011) 1150-1156.

[3] K.K. Sideris, P. Manita, Residual mechanical characteristics and spalling resistance of fiber reinforced self-compacting concretes exposed to elevated temperatures, Constr. Build. Mater. 41 (2013) 296-302.

[4] B. Luccioni, G. Ruano, F. Isla, R. Zerbino, G. Giaccio, A simple approach to model SFRC, Constr. Build. Mater. 37 (2012) 111-124.

[5] A. Naaman, H. Najm, Bond-slip mechanisms of steel fibers in concrete, ACI Mater. J. 88 (2) (1991) 135-145.

[6] V.M.C.F. Cunha, J.A.O. Barros, J.M. Sena Cruz, Pullout behavior of steel fibers in self-compacting concrete, J. Mater. Civ. Eng. 22 (1) (2010) 1-9.

[7] S. Abdallah, M. Fan, X. Zhou, Pull-out behaviour of hooked end steel fibres embedded in ultra-high performance mortar with various W/B ratios, Int. J. Concr. Struct. Mater. 11 (2) (2017) 301-313.

[8] Y. Lee, S.T. Kang, J.K. Kim, Pullout behavior of inclined steel fiber in an ultrahigh strength cementitious matrix, Constr. Build. Mater. 24 (2010) 2030-2041.

[9] G. Chanvillard, P. Aïtcin, Pullout behavior of corrugated steel fibers, Adv. Cem. Based Mater. 4 (1996) 28-41.

[10] I. Markovich, J.G. van Mier, J. Walraven, Single fiber pullout from hybrid fiber reinforced concrete, Heron 26 (3) (2001).

[11] P. Guerrero, A.E. Naaman, Effect of mortar fineness and adhesive agents on pullout response of steel fibers, ACI Mater. J. 97 (1) (2000) 12-20.

[12] T. Abu-Lebdeh, S. Hamoush, W. Heard, B. Zornig, Effect of matrix strength on pullout behavior of steel fiber reinforced very-high strength concrete composites, Constr. Build. Mater. 25 (2011) 39-46.

[13] B. Luccioni, F. Isla, R. Codina, D. Ambrosini, R. Zerbino, G. Giaccio, M.C. Torrijos, Effect of steel fibers on static and blast response of high strength concrete, Int. J. Impact Eng. 107 (2017) 23-37.

[14] A. Beglarigale, H. Yazıc1, Pull-out behavior of steel fiber embedded in flowable RPC and ordinary mortar, Constr. Build. Mater. 75 (2015) 255-265.

[15] C.S. Poon, Z.H. Shui, L. Lam, Compressive behavior of fiber reinforced highperformance concrete subjected to elevated temperatures, Cem. Concr. Res. 34 (2004) 2215-2222.

[16] A. Lau, M. Anson, Effect of high temperatures on high performance steel fibre reinforced concrete, Cem. Concr. Res. 36 (2006) 1698-1707.

[17] W. Zheng, B. Luo, Y. Wang, Compressive and tensile properties of reactive powder concrete with steel fibres at elevated temperatures, Constr. Build. Mater. 41 (2013) 844-851.

[18] W. Khaliq, V. Kodur, Thermal and mechanical properties of fiber reinforced high performance self-consolidating concrete at elevated temperatures, Cem. Concr. Res. 41 (2011) 1112-1122.

[19] R. Fike, V. Kodur, Enhancing the fire resistance of composite floor assemblies through the use of steel fiber reinforced concrete, Eng. Struct. 33 (2011) 2870 2878.

[20] P. Pliya, A.-L. Beaucour, A. Noumowé, Contribution of cocktail of polypropylene and steel fibres in improving the behaviour of high strength concrete subjected to high temperature, Constr. Build. Mater. 25 (2011) 1926-1934.

[21] J. Kim, G.-P. Lee, D.Y. Moon, Evaluation of mechanical properties of steel-fibrereinforced concrete exposed to high temperatures by double-punch test, Constr. Build. Mater. 79 (2015) 182-191.

[22] N. Bozkurt, The high temperature efect on fibre reinforced self compacting lightweight concrete designed with single and hybrid fibres, Acta Phys. Polonica A 125 (2014) 579-583. 
[23] G. Giaccio, R. Zerbino, Mechanical behaviour of thermally damaged high strength steel fibre reinforced concrete, Mater. Struct. 38 (277) (2005) 335342.

[24] A. Beglarigale, Ç. Yalçınkaya, H. Yiğiter, H. Yazıcı, Flexural performance of SIFCON composites subjected to high temperature, Constr. Build. Mater. 104 (2016) 99-108.

[25] Y.-S. Tai, H.-H. Pan, Y.-N. Kung, Mechanical properties of steel fiber reinforced reactive powder concrete following exposure to high temperature reaching $800{ }^{\circ} \mathrm{C}$, Nucl. Eng. Des. 241 (2011) 2416-2424.

[26] W. Zheng, H. Li, Y. Wang, Compressive stress-strain relationship of steel fiberreinforced reactive powder concrete after exposure to elevated temperatures, Constr. Build. Mater. 35 (2012) 931-940.

[27] Y.-C. Guo, J.-H. Zhang, G.-M. Chen, Z.-H. Xie, Compressive behaviour of concrete structures incorporating recycled concrete aggregates, rubber crumb and reinforced with steel fibre, subjected to elevated temperatures, J. Clean. Prod. 72 (2014) 193-203.

[28] S. Sanchayan, S.J. Foster, High temperature behaviour of hybrid steel-PVA fibre reinforced reactive powder concrete, Mater. Struct. 49 (3) (2015) 769-782.

[29] G.L. Balázs, É. Lublóy, Post-heating strength of fiber-reinforced concretes, Fire Saf. J. 49 (2012) 100-106.

[30] M. Colombo, M. di Prisco, R. Felicetti, SFRC exposed to high temperature: hot vs. residual characterization for thin walled elements, Cem. Concr. Compos. 58 (2015) 81-94.

[31] A. Caverzan, E. Cadoni, M. di Prisco, Dynamic tensile behaviour of high performance fibre reinforced cementitious composites after high temperature exposure, Mech. Mater. 59 (2013) 87-109.

[32] A. Farhad, B. Samali, Constitutive relationships for steel fibre reinforced concrete at elevated temperatures, Fire Technol. 50 (2014) 1249-1268.

[33] F. Isla, G. Ruano, B. Luccioni, Analysis of steel fibers pull-out. Experimental study, Constr. Build. Mater. 100 (2015) 183-193.

[34] E. Alizade, F. Jandaghi Alaee, S. Zabihi, Effect of steel fiber corrosion on mechanical properties of steel fiber reinforced concrete, Asian J. Civ. Eng. (BHRC) 17 (2) (2016) 147-158.

[35] C. Frazão, J. Barros, A. Camões, A.C. Alves, L. Rocha, Corrosion effects on pullout behavior of hooked steel fibers in self-compacting concrete, Cem. Concr. Res. 79 (2016) 112-122.

[36] M.E. Bossio, M.C. Torrijos, R. Zerbino, G. Giaccio, Pull out behaviour of macro synthetic fibres: effects of fibre type, matrix strength and microcracking, in: Proc. of Bond in concrete 2012: Bond, anchorage, Detailing, Fourth International Symposium 2 - Bond in new materials and under severe conditions, 2012, pp. 901-906.

[37] N. Banthia, C. Foy, Marine curing of steel fiber composites, J. Mater. Civ. Eng. 86 (1989) 86-96.

[38] A. Beglarigale, H. Yazıcı, The effect of alkali-silica reaction on steel fibermatrix bond characteristics of cement based mortars, Const. Build. Mater. 47 (2013) 845-860.
[39] R. Zerbino, M.C. Torrijos, G. Giaccio, On the residual properties of damaged FRC, Fibre Concrete 2017, IOP Conf. Series: Materials Science and Engineering, 246, 2017, https://doi.org/10.1088/1757-899X/246/1/012007.

[40] S. Abdallah, M. Fan, K.A. Cashell, Bond-slip behaviour of steel fibres in concrete after exposure to elevated temperatures, Constr. Build. Mater. 140 (1) (June 2017) 542-551.

[41] ASTM C39-05, Standard Test Method for Compressive Strength of Cylindrical Concrete Specimens, Annual Book of ASTM Standards 040223 (2009).

[42] ASTM C469, Standard Test Method for Static Modulus of Elasticity and Poisson Ratio of Concrete in Compression., ASTM International standard, (2014).

[43] EN14651, Test method for metallic fibered concrete - Measuring the flexural tensile strength (limit of proportionality (LOP), residual) 18, (2005).

[44] FIB, Model Code for Concrete Structures 2010, (2013).

[45] G. Giaccio, J.M. Tobes, R. Zerbino, Use of small beams to obtain design parameters of fibre reinforced concrete, Cem. Concr. Compos. 30 (4) (2008) 297-306.

[46] K. Marara, Ö. Erenb, İ. Yitmena, Compression specific toughness of normal strength steel fiber reinforced concrete (NSSFRC) and high strength steel fiber reinforced concrete (HSSFRC), Mater. Res. 14 (2) (2011) 239-247.

[47] Z.P. Bazant, M.F. Kaplan, Concrete at High Temperatures: Material Properties and Mechanical Models, Longman Group Limited, London, 1996.

[48] L.T. Phan, Fire performance of High-Strength concrete: a report of the State-ofthe-Art, NISTIR 5934 (1996) 1-115.

[49] B.M. Luccioni, M.I. Figueroa, R.F. Danesi, Thermo-mechanic model for concrete exposed to elevated temperatures, Eng. Struct. 25 (2003) 729-742.

[50] G. Baker, The effect of exposure to elevated temperatures on the fracture energy of plain concrete, Mater. Struct./Materiaux et Constructions 29 (1996) 383-388.

[51] P. Bamonte, P.G. Gambarova, A study on the mechanical properties of selfcompacting concrete at high temperature and after cooling, Mater. Struct. 45 (2012) 1375-1387.

[52] C.V. Nielsen, N. Bicanic, Residual fracture energy of high-performance and normal concrete subject to high temperatures, Mater. Struct./Matrriaux et Constructions 36 (2003) 515-521.

[53] K. Yu, J. Yu, Z. Lu, Q. Chen, Fracture properties of high-strength/highperformance concrete (HSC/HPC) exposed to high temperature, Mater. Struct. (2016), https://doi.org/10.1617/s11527-016-0804-x.

[54] N. Banthia, J.F. Trottier, Deformed steel fiber-cementitious matrix bond under impact, Cem. Concr. Res. 21 (1991) 158-168.

[55] Isla, F.A, 2014. Calderón, Modelo para hormigones reforzado con fibras de acero, Tesis Doctoral.

[56] G. Chanvillard, Model the pull out of wire-draw steel fibers, Cem. Concr. Res. 29 (1999) 1027-1037.

[57] Isla, F., Luccioni, B., 2014. Parámetros que definen el comportamiento del hormigón reforzado con fibras Mecánica Computacional XXXIII, pp. 12211235. 